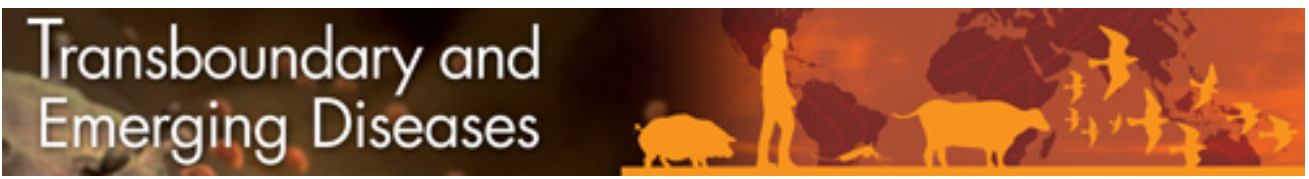

\title{
Emerging Influenza D virus infection in European livestock as determined in serology studies: are we underestimating its spread over the continent?
}

\begin{tabular}{|c|c|}
\hline Journal: & Transboundary and Emerging Diseases \\
\hline Manuscript ID & TBED-RW-757-20.R1 \\
\hline Manuscript Type: & Review \\
\hline $\begin{array}{r}\text { Date Submitted by the } \\
\text { Author: }\end{array}$ & $n / a$ \\
\hline Complete List of Authors: & $\begin{array}{l}\text { Gaudino, Maria; INRAE Occitanie-Toulouse, } \\
\text { Moreno, Ana; IZSLER, Virology } \\
\text { Snoeck, Chantal; Luxembourg Institute of Health, Department of } \\
\text { Infection and Immunity } \\
\text { Zohari, Siamak; National Veterinary Institute, Department of Virology } \\
\text { Saegerman, Claude; University of Liege Faculty of Veterinary Medicine, } \\
\text { Research Unit for Epidemiology and Risk Analysis applied to veterinary } \\
\text { sciences (UREAR-ULiège), Centre of Fundamental and Applied Research } \\
\text { for Animals and Health (FARAH) } \\
\text { O'Donovan, Tom; Department of Agriculture Food and the Marine } \\
\text { Laboratory Services } \\
\text { Ryan, Eoin; Virology } \\
\text { Zanni, Irene; IZSLER, Dignostic laboratory } \\
\text { Foni, Emanuela } \\
\text { Sausy, Aurelie; Luxembourg Institute of Science and Technology } \\
\text { Hübschen, Judith; Luxembourg Institute of Health, Department of } \\
\text { Infection and Immunity } \\
\text { Meyer, Gilles; National Veterinary School Toulouse } \\
\text { Chiapponi, Chiara; IZSLER, Parma, Sezione di Parma } \\
\text { Ducatez, Mariette; Université de Toulouse, INP, ENVT, UMR 1225, IHAP, } \\
\text { F-31076, Toulouse, France, UMR 1225 }\end{array}$ \\
\hline Subject Area: & $\begin{array}{l}\text { Disease control, Emerging diseases, Transmission, Veterinary } \\
\text { epidemiology, Virus }\end{array}$ \\
\hline
\end{tabular}

\section{SCHOLARONE ${ }^{\text {m }}$ Manuscripts}




\title{
Title: Emerging Influenza D virus infection in European livestock as determined in serology studies: are we underestimating its spread over the continent?
}

\begin{abstract}
Authors: M. Gaudino ${ }^{1,{ }^{*}}$, A. Moreno $2,{ }^{*}$, C.J. Snoeck ${ }^{3,}{ }^{*}$, S. Zohari ${ }^{4}$, C. Saegerman ${ }^{5}$, T. O'Donovan ${ }^{6}$, E. Ryan ${ }^{6}$, I. Zanni ${ }^{7}$, E. Foni ${ }^{7}$, A. Sausy ${ }^{3}$, J. Hübschen ${ }^{3}$, G. Meyer ${ }^{1}$, C. Chiapponi ${ }^{7}{ }^{*}$, M.F. Ducatez ${ }^{1}{ }^{*}$
\end{abstract}

Authors affiliations:

${ }^{1}$ IHAP, Université de Toulouse, INRAE, ENVT, Toulouse, France

2 Istituto Zooprofilattico Sperimentale della Lombardia e dell'Emilia Romagna "Bruno Ubertini", Brescia, Italy

${ }^{3}$ Clinical and Applied Virology group, Department of Infection and Immunity, Luxembourg Institute of Health, Esch-sur-Alzette, Luxembourg

${ }^{4}$ National Veterinary Institute, Uppsala, Sweden

${ }^{5}$ Fundamental and Applied Research for Animals and Health (FARAH) Center, University of Liège, Liège, Belgium

${ }^{6}$ Central Veterinary Research Laboratory, Celbridge, Co. Kildare, Ireland

7 Istituto Zooprofilattico Sperimentale della Lombardia e dell'Emilia Romagna "Bruno Ubertini", Parma, Italy

* These authors equally contributed to the study and should be considered as co-first/co-last authors 


\section{Summary (252 words)}

Influenza D virus (IDV) is a novel orthomyxovirus that was first isolated in 2011 in the United States from a swine exhibiting Influenza-like disease. To date, its detection is extended to all continents and in a broad host range: IDV is circulating in cattle, swine, feral swine, camelids, small ruminants and horses. Evidence also suggests a possible species jump to humans, underlining the issue of zoonotic potential. In Europe, serological investigations in cattle have partially allowed the understanding of the virus diffusion in different countries such as Italy, France, Luxembourg and Ireland. The infection is widespread in cattle but limited in other investigated species, consolidating the assumption of cattle as IDV primary host. We hypothesize that commercial livestock trade could play a role in the observed differences in IDV seroprevalence among these areas. Indeed, the overall level of exposure in cattle and swine in destination countries (e.g. Italy) is higher than in origin countries (e.g. France), leading to the hypothesis of a viral shedding following the transportation of young cattle abroad and thus contributing to larger diffusion at countries of destination. IDV large geographic circulation in cattle from Northern to more Southern European countries also supports the hypothesis of a viral spread through livestock trade. This review summarizes available data on IDV seroprevalence in Europe collected so far and integrates unpublished data from IDV European surveillance framework of the last decade. In addition, the possible role of livestock trade and biosecurity measures in this pathogen's spread is discussed.

Keywords: Influenza D virus, seroprevalence, epidemiology, zoonosis, livestock trade, cattle, swine, small ruminants 


\section{Introduction}

Influenza D virus (IDV) was isolated for the first time in 2011 in the United States from a swine exhibiting Influenza-like syndrome (Hause et al. 2013). It shared $50 \%$ of genetic identity with human Influenza C virus (ICV), leading to its provisional designation as C/swine/Oklahoma/1334/2011. In addition, this novel virus showed no reassortment with the other genera of Influenza viruses (Influenza A and B viruses, IAV and IBV, or ICV) (Hause et al. 2014). As a consequence, the International Committee on Taxonomy of Viruses (ICTV) decided in 2016 to create a new genus in the Influenza virus family. The new genus is currently known as Influenza D virus, extending therefore the Orthomyxoviridae from six to seven genera. Based on their similarity in terms of genetic and morphological structures, some authors suggested the possibility of IDV derivation from ICV (Su et al. 2017). Indeed, the nucleotide identity between ICV and IDV is 50\% for the Hemagglutinin Esterase-Fusion segment (HEF), the most variable segment among Influenza viruses, and 70\% for PB1 (Polymerase basic protein 1), the most conserved segment (Hause et al., 2013). Similarities between ICV and IDV include the genomic composition of seven segments and both only have one major surface glycoprotein that fulfils the functions of receptor recognition and binding, its destruction and the fusion between the virions and the host cell membranes. On the contrary, IAV and IBV are composed of eight genomic segments and these functions are accomplished by two different proteins, the hemagglutinin (HA), which binds to the host cell receptors and mediates the membrane fusion, and neuraminidase (NA) that allows for receptor destroying and new viral particles release (Asha and Kumar 2019).

So far, two major circulating IDV lineages have been described in North America and Europe, often designated as $\mathrm{D} / \mathrm{OK}$ and $\mathrm{D} / 660$. Reassortment events between these two lineages were also revealed (Chiapponi et al. 2019; Collin et al. 2015). In Europe, a third genetically divergent lineage was described in France in 2012 and Ireland in 2014 (designated as D/bovine/France/2986/2012 and D/bovine/Ireland/007780/2014 respectively). Though, further IDV sequences are needed to assess if another different lineage is circulating in Europe. In addition, other genetically divergent lineages are present in Japan and they have not been reported on other continents to date (Murakami et al. 2016, 2020)(Hayakawa et al. 2020). 
So far, IDV seems to have a broad host range and has been described almost on all continents, showing an intercontinental transmission. Despite its first isolation from swine, cattle is currently considered as IDV principal host. Indeed, various studies report a high prevalence of IDV in this species (Luo et al., 2017; O’Donovan, Donohoe, Ducatez, Meyer, \& Ryan, 2019; Oliva et al., 2019; Rosignoli et al., 2017) whereas historically cattle had never been considered a potential reservoir of Influenza A viruses (Sreenivasan et al. 2019). Currently, the list of susceptible species include cattle, swine (Foni et al. 2017; Gorin et al. 2019), small ruminants (O’Donovan et al. 2019; Oliva et al. 2019; Quast et al. 2015), camelids (Murakami et al. 2019; Salem et al. 2017), feral swine (Ferguson et al. 2018) and horses (Nedland et al. 2018). The emergence of the novel IDV in pigs initially raised public health concerns, as swine is a wellknown host of other zoonotic Influenza viruses. However, whether IDV could be a threat to human is still unclear. Studies in the ferret model, where IDV replicates efficiently (Hause et al. 2013), as well as IDV receptors characterization (Song et al. 2016), suggest that humans may be susceptible. Furthermore, IDV replicates well in a human airway epithelium model (Holwerda et al. 2019) and its genetic material has been detected in a bioaerosol sample collected at an airport (Bailey et al. 2018), in a hospital emergency room (Choi et al. 2018), as well as in a nasal swab of a farmer working on a pig farm in Malaysia (Borkenhagen et al. 2018). Serologic surveys conducted in persons with occupational contact with cattle in Florida (White et al. 2016) and in the general population in Italy (Trombetta et al. 2019) suggested a zoonotic potential. In contrast, a prevalence of only $1.3 \%$ of anti-IDV antibodies was initially observed in a Canadian elderly cohort (Hause et al. 2013) and cross-reactivity between anti-ICV and IDV antibodies was highlighted in human and camelids, suggesting that further controls and optimizations should be carried out in the serology assays before conclusions can be drawn on IDV seropositivity in these species (Eckard 2016; Salem et al. 2017). Wide epidemiological investigations are still lacking to assess a risk level for humans and they could provide additional insights about the real IDV zoonotic potential.

Epidemiological investigations suggest cattle to be IDV primary host and, so far, the virus has been detected both in healthy and diseased animals. Nevertheless, studies conducted through metagenomic approaches suggested its implication in Bovine Respiratory Disease Complex (BRDC) (Mitra et al. 2016; Ng et al. 2015; Zhang et al. 2019), one of the most concerning health issues in cattle industry that has multifactorial aetiology and causes major economic losses. 
Experimental infections showed mild to moderate clinical signs in cattle, as well as direct contact and aerosol transmission among animals (Ferguson et al. 2016; Salem et al. 2019). The real implication of IDV on BRDC severity in the field is still not clear and further studies would be needed to demonstrate its role.

In Europe, IDV was first reported in cattle in France in 2012 (Ducatez, Pelletier, and Meyer 2015) and was then detected in surrounding countries Italy (Chiapponi et al. 2016) and Luxembourg (Snoeck et al. 2018), but also in Ireland (Flynn et al. 2018) and the UK (Dane et al. 2019). On this continent, as in other parts of the world, the livestock trade across national borders each year is of great importance. Livestock trade essentially includes import and export of live animals to neighbouring countries for production (fattening), breeding and slaughtering. This sector substantially contributes to the European economy, representing almost half of the total agricultural activity (Eurostat). In a "One Health" context, livestock health is a major link in the global health chain. Animal-based product consumption has been a fast-growing component of food industry in the last decades, particularly in some developing countries in Asia and South America but concerning also industrialized countries. A continuous surveillance on emerging livestock pathogens is thus required in order to ensure animal wellbeing but also to prevent health-related challenges in a more complex setting of animal-tohuman pathogen transmission prevention.

The aim of this review is to summarize IDV infection spread in the European continent in different animal species. The review focuses on serological data obtained during the last ten years of surveillance and includes unpublished data coming from the consortium for European surveillance of this novel virus. In addition, the role of livestock trade in IDV transmission between different countries is discussed.

\section{IDV seroprevalence in European livestock: a widespread infection in cattle with limited diffusion in swine and small ruminants}

IDV seroprevalence in different species (which will be detailed in the following paragraphs) was mainly assessed by $\mathrm{HI}$ assay (Hemagglutination Inhibition). In all cases, a threshold of positivity was set at antibody titers $\geq 1: 20$. ELISA test (Enzyme-linked Immunosorbent Assay) 
was also used. A summary of technical details and results for each study is presented in Table 1 (Cattle), Table 2 (Swine) and Table 3 (Small ruminants).

\section{Cattle}

In France, a serosurvey was carried out on bovine sera ( $n=3703)$ collected from 2014 to 2018 in 5 French regions (Oliva et al. 2019). Sera were tested by $\mathrm{HI}$ assay (with $1 \%$ solution of horse red blood cells). All animals were older than 1-year of age, excluding interference with maternally derived antibodies. The overall resulting seroprevalence was $47.2 \%$ but results varied depending on the geographical region (with seroprevalence ranging from 31.0 to 70.0\%). In Italy, the overall reported IDV seroprevalence in cattle was higher than in France. Cohorts of bovine sera coming from both active $(n=420)$ (Rosignoli et al., 2017) and both active/passive surveillance $(n=315)$ (Moreno et al. 2019) were tested for anti-IDV antibodies by using $\mathrm{HI}$ assay ( $0.5 \%$ solution of turkey red blood cells) and solid-phase competitive ELISA (Moreno et al, 2019). Overall resulting seroprevalence was $92.4 \%$ and $74 \%$, respectively. In addition, an observational cohort study conducted on 914 cattle samples collected in 20162018 showed a seroprevalence of 69\%. In Luxembourg high IDV seroprevalence (80.2-82.5\%) was found in cattle sera ( $n=450$ and $n=108$ ) collected in 2016 (Snoeck et al. 2018) and 2019 respectively. Authors reported no difference between IDV seroprevalence in dairy and meat production cattle. Similar seroprevalence rates were found when testing the same 2016 cohort by $\mathrm{HI}(80.2 \%)$ or solid-phase competitive ELISA (81.8\%). Finally, in 2017 in Ireland (O'Donovan et al. 2019) sera were collected from slaughterhouses across the country ( $n=1219)$ and screened for anti-IDV antibodies. An additional cohort of sera collected in 2016 and 2017 for diagnostic purposes to screen for antibodies to bovine respiratory disease (BRD) pathogens was also tested for IDV antibodies ( $n=1183)$. A high difference was found in terms of seroprevalence between the two cohorts, with $94.6 \%$ and $64.9 \%$ for active and passive surveillance, respectively. Relevant differences in overall IDV seroprevalence in cattle were also found in Italy based on the type of surveillance (active or passive), suggesting that it could be a relevant factor that should be taken into consideration to assess future sampling plans. Available serological results in cattle in Europe are summarized in Table 1.

\section{Swine}


A different scenario emerged from serological studies conducted on serum samples collected in swine farms. A serosurvey across France was conducted on 2090 sera collected from 102 different farms between 2012 and 2018 (Gorin et al. 2019). Herds were mostly located in Brittany region, known to have the highest pig density in France. Samples were also collected in Nouvelle Aquitaine, Occitanie, Hauts-de-France, Normandie, Pays de la Loire and Corsica regions. While anti-IDV antibodies in cattle were found in most of these regions (Oliva et al. 2019), positive swine sera were found only from Brittany and Corsica regions. The overall IDV seroprevalence was $1.6 \%$ (represented by 31 positive samples on a total of 2090 tested sera). In these two regions, seroprevalence varied from 3.3 to $73.3 \%$ in Brittany and $7.1-16.7 \%$ in Corsica. In Brittany two herds with high within-herd seroprevalence (73.3\% and 3.3\%, where samples were collected in 2014 and 2015 respectively) were re-tested in 2017 to assess virus persistence but they then exhibited 13.3\% and 3.3\%. In Italy, cohorts from 2009 to 2018 coming from active and passive surveillance were screened for anti-IDV antibodies. All herds originated from the Po Valley (Northern Italy), one of the most intensive pig farming areas in Europe. Overall IDV seroprevalence ranged from 0.6 to $11.7 \%$, depending on the year of sampling (Foni et al. 2017). IDV monitoring was also conducted on wild boars from the Alpine and Northern Apennine areas. A total of 1350 samples collected in 2018 and 2019 was tested with a low prevalence (1,92\%). Details of sera tested for Italian cohorts for each year are available in Table 2. In Luxembourg, the first cohort from 2012 ( $n=258)$ was found seronegative, then a second cohort $(n=287)$ including sera collected at slaughter in 2014-2015 harboured 5.9\% seroprevalence (Snoeck et al. 2018). In Ireland, a seroprevalence of 5.8\% was found in swine ( $n=377$ ) (O'Donovan et al. 2019). Results from serological studies in pigs are summarized in Table 2.

\section{Small ruminants}

So far, limited serological investigations have been performed on small ruminants. In France, sheep and goat sera were tested within the same framework as IDV serosurveillance in cattle (Oliva et al. 2019). In Brittany, no evidence of past exposure was found in sheep sera cohorts $(n=164)$, whereas in goats $(n=104) 5.8 \%$ of samples tested positive. In Hauts-de-France, 5.5\% $(n=306)$ and $1.3 \%(n=80)$ of sheep and goats were seropositive, respectively. In Occitanie, the overall seroprevalence was $0.4 \%(n=960)$ for sheep and $2.9 \%(n=441)$ for goats. The authors 
reported a significant difference between IDV seroprevalence in cattle and small ruminants in these regions. Similar results in seroprevalence were found in Italy in sheep $(n=506)$ and goats ( $n=188$ ) cohorts of sera collected in $2016-2017$, with $6.3 \%$ and $3.1 \%$ of tested sera IDV seropositive, respectively (unpublished data). A very low prevalence of $0.98 \%$ was observed when wild ungulates $(n=204)$ collected under the Italian wildlife monitoring program were tested (unpublished data). Finally, in Ireland a seroprevalence of $4.5 \%(n=288)$ was reported in sheep (O'Donovan et al. 2019). Results from serological studies in small ruminants are summarized in Table 3.

Taken together, high IDV seroprevalence in cattle suggested the potential role of the species as primary host of this emerging virus, while available data on pigs and small ruminants suggest that its circulation is limited in these species. Overall the median IDV seroprevalence was significantly higher in cattle than in swine and small ruminants (Kruskal-Wallis equalityof-populations rank test; chi-squared $=24$ with 2 d.f. and $p$-value $=0.0001$ ) but they are not significant between swine and small ruminants (Kruskal-Wallis equality-of-populations rank test; chi-squared $=0.009$ with 1 d.f. and $p$-value $=0.92$ ). High IDV seroprevalence in European cattle is consistent with the findings generated in other continents: in the United States the overall IDV seroprevalence in cattle was $77.5 \%$ nationally, ranging from $47.7 \%$ to $84.6 \%$ depending on the region (Silveira et al. 2019), whereas in South America 73\% of tested farms had at least one positive animal (Alvarez et al. 2020). The infection seems less extended in cattle in African countries (Salem et al. 2017)(Fusade-Boyer et al. 2020) than in Europe or America. This could be possibly due to a lower density of animals in cattle industry, as cattle density was found to be a major risk factor for IDV infection occurrence (Fusade-Boyer et al. 2020). Although some studies highlighted IDV circulation in Asian countries by using molecular tools (Murakami et al. 2016) (Zhai et al. 2017), little data on IDV seroprevalence in cattle is available for this continent at the moment. In Japan, a recent study highlighted IDV seroprevalence ranging from $45 \%$ to $71 \%$ in sera collected in Hokkaido prefecture from 2009 to 2018 (Hayakawa et al. 2020), underlining the virus circulation on the island since at least ten years.

\section{Overview on livestock trade between different countries in Europe}


The European Union has a substantial livestock population: in 2018, Europe counted 148 million heads of pigs, 87 of cattle, 98 of sheep and goats (Eurostat 2018). The most important cattle producer is France, reaching 19 million heads of animals in 2018 (Eurostat), followed by Germany (12 million heads). A considerable number of animals is then exported to neighbouring countries, mostly for production but also for slaughtering and for breeding. In $2018,3,073,082$ cattle heads were traded among EU countries for production, 654,938 heads for slaughtering and 607,226 for breeding. The most important movements of cattle for production took place from France to Italy (almost one million heads), followed by Germany to the Netherlands (531,597 heads), France to Spain $(420,774$ heads) and Belgium to the Netherlands $(153,508$ heads). This makes Italy, Netherlands and Spain the three most important cattle importers in Europe and France and Germany the leading countries for export. A different situation is observed in export for slaughtering: the Netherlands is the leading country for export, Austria and Belgium for import. Cattle trade between different EU countries is summarized in a trade matrix in Figure 1 and on a geographic map in Figure 3.

With regards to swine production, Spain and Germany are leading countries for pig farming, reaching a population of 30,804,102 and 26,445,400 heads in 2018, respectively. In Europe, the total number of traded pigs has greater importance than cattle: in $2018,8,388,712$ heads were traded for slaughter, $24,279,371$ were traded for production and 752,501 for breeding. Among pigs traded for production, the vast majority is exported abroad by Denmark, with more than 14 million heads per year, followed by Netherlands ( 7 million per year). European countries importing most swine are Germany (almost 11 million heads per year) and Poland (7 million heads per year) (Eurostat). Swine trade between different EU countries is summarized in a trade matrix in Figure 2.

Among small ruminants, sheep occupy a much more important place on the market of traded animals than goats. Sheep are mostly traded in Europe for slaughtering, with a total of 2,442,066 heads in 2018 (mostly from France to Spain, UK to Ireland and Hungary to Italy). Also 932,946 heads were traded for fattening (mostly from Spain to Portugal and from Romania to Greece and Hungary). Trade for sheep breeding concerned only 48,104 heads overall. Finally, 25,330 goats were traded for slaughtering, 8,409 for fattening and 4,840 for breeding (Eurostat). 


\section{Discussion}

Livestock trade is of great economic importance, allowing animal-origin products offer at affordable price for the final consumer, as well as a substantial contribution to the local economy and development. Nevertheless, live animal transport can also lead to health issues that are often only noticed at the destination country. Transport is a very stressful event for animals, with a clear impact on cattle health and production and has a well-documented role in BRDC onset (Buckham Sporer et al. 2008; Van Engen and Coetzee 2018). Transportation can cause immunosuppression in young calves, allowing for the colonization by opportunistic pathogens and sometimes causing severe disease (Earley, Buckham Sporer, and Gupta 2017). Pathogen shedding following transportation has been demonstrated to increase, not only for bacteria such as Mannhemia haemolytica, Mycoplasma bovis and Pasteurella multocida but also for viruses such as Bovine Coronavirus (BCoV) and Bovine Respiratory Syncytial Virus (BRSV) (Cirone et al. 2019). Most importantly, in a study conducted in Mississippi, young calves were sampled before and after admission in herd facility for anti-IDV antibodies and viral RNA detection (Ferguson et al. 2015). Results showed that IDV infection could occur after arrival in the conditioning yard, as some calves tested negative before the arrival by RT-PCR but were positive one week later. In addition, the same study showed that almost all neonatal calves were able to acquire anti-IDV antibodies through colostrum after birth but the antibody titers seemed to decrease with age, as at 6 to 8 months only 3.7 to $11.5 \%$ of the same calves were IDV seropositive. Seropositivity increased then at 1-year age, suggesting that calves mostly encounter IDV between 6 months to one year of age. In Europe, this often corresponds to the period where calves are transported abroad for fattening but also slaughtering, strengthening the hypothesis that trading of young calves in a period of immunologic weakness could contribute to pathogen shedding in the herd of arrival.

In this context, biosecurity is an important measure to prevent livestock pest and disease introduction in farms. In European regulations, biosecurity is defined in the "Animal Health Law" and other legislation aimed at minimising animal disease contained in Regulation (EU) 2016/429. On a practical level, some of the recommended practices include isolation for at least 4 weeks for all purchased animals arriving at a farm but also regular equipment sanitation, correct storage of food and water and, when applicable, preventive measures such as vaccination. There are different individuals that play a role in biosecurity implementation, 
including not only government authorities and legislators but above all farmers and veterinarians. It is often assumed that farmers have the necessary resources and knowledge to minimize the risk of disease introduction. In a survey conducted on dairy cattle farmers in Ireland, most of the interviewees declared that biosecurity is important. Still, half of them also declared a lack of necessary knowledge that would help them in improving their biosecurity measures (Sayers et al. 2013). In addition, a lack of trust of farmers towards governing authorities was shown, arising the belief that biosecurity is primarily a government responsibility, and leading to inobservance of recommended good practices (Higgins et al. 2018).

As IDV is an emerging pathogen, its veterinary monitoring is still partial. Its novelty and the possible absence of clinical manifestation in infected cattle impair early pathogen detection without specific molecular tools and active surveillance. Although IDV does not cause concerns for cattle farming to date despite its implication in BRDC, there is a need for a more rigorous surveillance and implementation of biosecurity measures. In particular, observance of recommended practices such as quarantine for purchased animals and testing on the arriving lots is once more advised (Damiaans et al. 2020), as a survey showed that only half of the interviewed farmers apply the quarantine practice and only $7 \%$ test animals after purchase (Sayers et al. 2013). Among interviewed farmers answering "no" to the post-purchase testing, $21 \%$ of them thought it was of "no benefit", $20 \%$ declared "not to know what to test for", $45 \%$ were never advised to do so and $13 \%$ complained about the cost of testing.

Interestingly, the overall IDV prevalence was found to be lower in countries that mainly export cattle (e.g. France, with a seroprevalence ranging from $33 \%$ to $64 \%$ depending on the region) than in countries that mainly import cattle from abroad, from instance Italy (from $65 \%$ to 95\%). This suggests that cattle may come in contact with IDV during or just after transportation and that viral shedding mainly occurs after transportation in the destination countries, contributing to larger diffusion than in origin countries. The role of inter-herd livestock exchanges in disease spread is already known, being of particular concern for airborne transmission pathogens (Pandit et al. 2016). The assumption of IDV spread though livestock trade is also strengthened by the large diffusion in cattle across all Europe, from Northern to more Southern. The high movement of cattle from France to Italy could have contributed to IDV spread in this country. IDV introduction in Ireland and Luxembourg could have occurred 
through the import of infected cattle from France or other European countries. Considering the large number of traded animals every year, we speculate that IDV is probably present also outside the four territories surveyed, as already suggested previously for countries bordering Luxembourg given frequent cross-border grazing and trade (Snoeck et al., 2018). A surveillance network extended to other EU members would provide more information about the real spread of this emerging pathogen, in particular in countries importing cattle from areas where IDV is already known to circulate. For instance, IDV surveillance could be useful in leading countries for cattle import in Europe, such as Spain and the Netherlands, where a similar (or even higher) seroprevalence than the origin country could be hypothesized. In addition, a longitudinal study with monitoring of IDV in calves traded from origin country to arrival country would provide additional insight about the real shedding of this pathogen during transport. IDV surveillance implementation is justified by its zoonotic potential and its possible implication in BRDC aggravation.

\section{Conclusion}

Influenza D virus infection in cattle has spread across different countries in Europe. Surveillance in countries where IDV presence has not been investigated is required in order to understand the real spread of the virus. IDV role in BRDC onset, especially after stress transport experience, is still not clear to date and further analysis could help in determining its actual implication in diseased cattle. We hypothesize the role of livestock trade in the observed differences of IDV seroprevalence among European countries where data is available. In addition to surveillance, implementation of biosecurity measures are once more emphasized (Damiaans et al. 2020), especially at arrival of young cattle in a facility, in order to limit the geographical spread of this emerging respiratory pathogen with zoonotic potential.

\section{Acknowledgements}

This study was performed under the Grant Agreement Number GP/EFSA/AFSCO/2017/01 GA04, entitled "Risk assessment for influenza D in Europe". This work was co-funded by the French National Agency for Research, project ANR-15-CE35-0005 "FLUD", the Italian Ministry of Health grant IZS LER 2015006 RC and Istituto Zooprofilattico Sperimentale della Lombardia e dell'Emilia Romagna, the Luxembourg Institute of Health, the Ministère de l'Agriculture, 
Viticulture et Développement Rural du Luxembourg, the Department of Agriculture, Food and the Marine, Ireland. The article reflects only the author's view and the EFSA Authority is not responsible for any use that may be made of the information it contains.

\section{Ethics statement}

The authors confirm that the ethical policies of the journal, as noted on the journal's author guidelines page, have been adhered to. No ethical approval was required as this is a review article.

\section{Conflict of interest statement}

The authors declare that they have no competing interests

\section{Data sharing and accessibility}

For the most part, data sharing is not applicable to this article as little new data were created or analyzed in this study. The unpublished data that support the findings of this study are available from the corresponding author upon reasonable request.

\section{References}

Alvarez, Ignacio J., Marcelo Fort, Juan Pasucci, Fabiana Moreno, Hugo Gimenez, Katarina Näslund, Sara Hägglund, Siamak Zohari, and Jean François Valarcher. 2020. "Seroprevalence of Influenza D Virus in Bulls in Argentina." Journal of Veterinary Diagnostic Investigation 32(4):585-88.

Asha, Kumari, and Binod Kumar. 2019. "Emerging Influenza D Virus Threat: What We Know so Far!" Journal of Clinical Medicine 8(2):192.

Bailey, Emily S., Jessica Y. Choi, Juliana Zemke, Myagmarsukh Yondon, and Gregory C. Gray. 2018. "Molecular Surveillance of Respiratory Viruses with Bioaerosol Sampling in an Airport." Tropical Diseases, Travel Medicine and Vaccines 4(1). 
Borkenhagen, Laura K., Kerry A. Mallinson, Rick W. Tsao, Siaw Jing Ha, Wei Honn Lim, Teck Hock Toh, Benjamin D. Anderson, Jane K. Fieldhouse, Sarah E. Philo, Kuek Sen Chong, William G. Lindsley, Alejandro Ramirez, James F. Lowe, Kristen K. Coleman, and Gregory C. Gray. 2018. "Surveillance for Respiratory and Diarrheal Pathogens at the Human-Pig Interface in Sarawak, Malaysia." PLoS ONE 13(7).

Buckham Sporer, K. R., P. S. D. Weber, J. L. Burton, B. Earley, and M. A. Crowe. 2008. "Transportation of Young Beef Bulls Alters Circulating Physiological Parameters That May Be Effective Biomarkers of Stress." Journal of Animal Science 86(6):1325-34.

Chiapponi, Chiara, Silvia Faccini, Alice Fusaro, Ana Moreno, Alice Prosperi, Marianna Merenda, Laura Baioni, Valentina Gabbi, Carlo Rosignoli, Giovanni L. Alborali, Lara Cavicchio, Isabella Monne, Camilla Torreggiani, Andrea Luppi, and Emanuela Foni. 2019. "Detection of a New Genetic Cluster of Influenza D Virus in Italian Cattle." Viruses 11(12).

Chiapponi, Chiara, Silvia Faccini, Aurora De Mattia, Laura Baioni, Ilaria Barbieri, Carlo Rosignoli, Arrigo Nigrelli, and Emanuela Foni. 2016. "Detection of Influenza D Virus among Swine and Cattle, Italy." Emerging Infectious Diseases 22(2):352-54.

Choi, Jessica Y., Juliana Zemke, Sarah E. Philo, Emily S. Bailey, Myagmarsukh Yondon, and Gregory C. Gray. 2018. "Aerosol Sampling in a Hospital Emergency Room Setting: A Complementary Surveillance Method for the Detection of Respiratory Viruses." Frontiers in Public Health 6.

Cirone, Francesco, Barbara Padalino, Daniele Tullio, Paolo Capozza, Michele Lo Surdo, Gianvito Lanave, and Annamaria Pratelli. 2019. "Prevalence of Pathogens Related to Bovine Respiratory Disease before and after Transportation in Beef Steers: Preliminary Results." Animals 9(12).

Collin, Emily A., Zizhang Sheng, Yuekun Lang, Wenjun Ma, Ben M. Hause, and Feng Li. 2015. "Cocirculation of Two Distinct Genetic and Antigenic Lineages of Proposed Influenza D Virus in Cattle." Journal of Virology 89(2):1036-42.

Damiaans, Bert, Véronique Renault, Steven Sarrazin, Anna Catharina Berge, Bart Pardon, Claude Saegerman, and Jeroen Dewulf. 2020. "A Risk-Based Scoring System to Quantify Biosecurity in Cattle Production." Preventive Veterinary Medicine 179.

Dane, Hannah, Catherine Duffy, Maria Guelbenzu, Ben Hause, Sean Fee, Fiona Forster, Michael J. McMenamy, and Ken Lemon. 2019. "Detection of Influenza D Virus in Bovine Respiratory Disease Samples, UK." Transboundary and Emerging Diseases 66(5):2184-87.

Ducatez, Mariette F., Claire Pelletier, and Gilles Meyer. 2015. "Influenza d Virus in Cattle, France, 
2011-2014." Emerging Infectious Diseases 21(2):368-71.

Earley, B., K. Buckham Sporer, and S. Gupta. 2017. “Invited Review: Relationship between Cattle Transport, Immunity and Respiratory Disease." Pp. 486-92 in Animal. Vol. 11. Cambridge University Press.

Eckard, Laura Evelyn. 2016. "Assessment of the Zoonotic Potential of a Novel Bovine Influenza Virus." Van Engen, N. K., and J. F. Coetzee. 2018. "Effects of Transportation on Cattle Health and Production: A Review." Animal Health Research Reviews 19(2):142-54.

Ferguson, Lucas, Laura Eckard, William B. Epperson, Li Ping Long, David Smith, Carla Huston, Suzanne Genova, Richard Webby, and Xiu Feng Wan. 2015. “Influenza D Virus Infection in Mississippi Beef Cattle." Virology 486:28-34.

Ferguson, Lucas, Kaijian Luo, Alicia K. Olivier, Fred L. Cunningham, Sherry Blackmon, Katie HansonDorr, Hailiang Sun, John Baroch, Mark W. Lutman, Bianca Quade, William Epperson, Richard Webby, Thomas J. DeLiberto, and Xiu Feng Wan. 2018. “Influenza D Virus Infection in Feral Swine Populations, United States." Emerging Infectious Diseases 24(6):1020-28.

Ferguson, Lucas, Alicia K. Olivier, Suzanne Genova, William B. Epperson, David R. Smith, Liesel Schneider, Kathleen Barton, Katlin McCuan, Richard J. Webby, and Xiu-Feng Wan. 2016. “Pathogenesis of Influenza D Virus in Cattle." Journal of Virology 90(12):5636-42.

Flynn, Orla, Clare Gallagher, Jean Mooney, Claire Irvine, Mariette Ducatez, Ben Hause, Guy McGrath, and Eoin Ryan. 2018. "Influenza D Virus in Cattle, Ireland." Emerging Infectious Diseases 24(2):389-91.

Foni, Emanuela, Chiara Chiapponi, Laura Baioni, Irene Zanni, Marianna Merenda, Carlo Rosignoli, Constantinos S. Kyriakis, Mario Vittorio Luini, Maria Lucia Mandola, Luca Bolzoni, Arrigo Daniele Nigrelli, and Silvia Faccini. 2017. "Influenza D in Italy: Towards a Better Understanding of an Emerging Viral Infection in Swine." Scientific Reports 7(1).

Fusade-Boyer, Maxime, Pidemnéwé S. Pato, Mathias Komlan, Koffi Dogno, Komla Batawui, Emilie GoMaro, Pamela McKenzie, Claire Guinat, Aurélie Secula, Mathilde Paul, Richard J. Webby, Annelise Tran, Agnès Waret-Szkuta, and Mariette F. Ducatez. 2020. "Risk Mapping of Influenza D Virus Occurrence in Ruminants and Swine in Togo Using a Spatial Multicriteria Decision Analysis Approach." Viruses 12(2):16-18.

Gorin, Stéphane, Christelle Fablet, Stéphane Quéguiner, Nicolas Barbier, Frédéric Paboeuf, Séverine Hervé, Nicolas Rose, and Gaëlle Simon. 2019. “Assessment of Influenza D Virus in Domestic Pigs 
and Wild Boars in France: Apparent Limited Spread within Swine Populations despite Serological Evidence of Breeding Sow Exposure." Viruses 12(1).

Hause, Ben M., Emily A. Collin, Runxia Liu, Bing Huang, Zizhang Sheng, Wuxun Lu, Dan Wang, Eric A. Nelson, and Feng Li. 2014. “Characterization of a Novel Influenza Virus in Cattle and Swine: Proposal for a New Genus in the Orthomyxoviridae Family." MBio 5(2).

Hause, Ben M., Mariette Ducatez, Emily A. Collin, Zhiguang Ran, Runxia Liu, Zizhang Sheng, Anibal Armien, Bryan Kaplan, Suvobrata Chakravarty, Adam D. Hoppe, Richard J. Webby, Randy R. Simonson, and Feng Li. 2013. "Isolation of a Novel Swine Influenza Virus from Oklahoma in 2011 Which Is Distantly Related to Human Influenza C Viruses." PLoS Pathogens 9(2).

Hayakawa, Jun, Tomomi Masuko, Tae Takehana, and Tohru Suzuki. 2020. "Genetic and Antigenic Characterization and Retrospective Surveillance of Bovine Influenza D Viruses Identified in Hokkaido, Japan from 2018 to 2020." Viruses 12(8):877.

Higgins, Vaughan, Melanie Bryant, Marta Hernandez-Jover, Luzia Rast, and Connar McShane. 2018. "Devolved Responsibility and On-Farm Biosecurity : Practices of Biosecure Farming Care in Livestock Production." Sociologia Ruralis 58(1).

Holwerda, Melle, Jenna Kelly, Laura Laloli, Isabel Stürmer, Jasmine Portmann, Hanspeter Stalder, and Ronald Dijkman. 2019. "Determining the Replication Kinetics and Cellular Tropism of Influenza D Virus on Primary Well-Differentiated Human Airway Epithelial Cells." Viruses 11(4).

Luo, Junrong, Lucas Ferguson, David R. Smith, Amelia R. Woolums, William B. Epperson, and Xiu Feng Wan. 2017. "Serological Evidence for High Prevalence of Influenza D Viruses in Cattle, Nebraska, United States, 2003-2004." Virology 501:88-91.

Mitra, Namita, Natalia Cernicchiaro, Siddartha Torres, Feng Li, and Ben M. Hause. 2016.

"Metagenomic Characterization of the Virome Associated with Bovine Respiratory Disease in Feedlot Cattle Identified Novel Viruses and Suggests an Etiologic Role for Influenza D Virus." Journal of General Virology 97(8):1771-84.

Moreno, Ana, Davide Lelli, Antonio Lavazza, Enrica Sozzi, Irene Zanni, Chiara Chiapponi, Emanuela Foni, Lorenzo Capucci, and Emiliana Brocchi. 2019. "MAb-Based Competitive ELISA for the Detection of Antibodies against Influenza D Virus." Transboundary and Emerging Diseases 66(1):268-76.

Murakami, Shin, Maiko Endoh, Tomoya Kobayashi, Akiko Takenaka-Uema, James K. Chambers, Kazuyuki Uchida, Masugi Nishihara, Benjamin Hause, and Taisuke Horimoto. 2016. "Influenza d 
Virus Infection in Herd of Cattle, Japan." Emerging Infectious Diseases 22(8):1517-19.

Murakami, Shin, Tomoha Odagiri, Simenew Keskes Melaku, Boldbaatar Bazartseren, Hiroho Ishida, Akiko Takenaka-Uema, Yasushi Muraki, Hiroshi Sentsui, and Taisuke Horimoto. 2019. "Influenza D Virus Infection in Dromedary Camels, Ethiopia." Emerging Infectious Diseases 25(6):1224-25.

Murakami, Shin, Ryota Sato, Hiroho Ishida, Misa Katayama, Akiko Takenaka-Uema, and Taisuke Horimoto. 2020. "Influenza d Virus of New Phylogenetic Lineage, Japan." Emerging Infectious Diseases 26(1):168-71.

Nedland, H., J. Wollman, C. Sreenivasan, M. Quast, A. Singrey, L. Fawcett, J. Christopher-Hennings, E. Nelson, R. S. Kaushik, D. Wang, and F. Li. 2018. "Serological Evidence for the Co-Circulation of Two Lineages of Influenza D Viruses in Equine Populations of the Midwest United States." Zoonoses and Public Health 65(1):e148-54.

$\mathrm{Ng}$, Terry Fei Fan, Nikola O. Kondov, Xutao Deng, Alison Van Eenennaam, Holly L. Neibergs, and Eric Delwart. 2015. "A Metagenomics and Case-Control Study To Identify Viruses Associated with Bovine Respiratory Disease." Journal of Virology 89(10):5340-49.

O’Donovan, Tom, Leah Donohoe, Mariette F. Ducatez, Gilles Meyer, and Eoin Ryan. 2019.

"Seroprevalence of Influenza D Virus in Selected Sample Groups of Irish Cattle, Sheep and Pigs." Irish Veterinary Journal 72(1).

Oliva, Justine, Amit Eichenbaum, Jade Belin, Maria Gaudino, Jean Guillotin, Jean Pierre Alzieu, Philippe Nicollet, Roland Brugidou, Eric Gueneau, Evelyne Michel, Gilles Meyer, and Mariette F. Ducatez. 2019. "Serological Evidence of Influenza D Virus Circulation among Cattle and Small Ruminants in France." Viruses 11(6).

Pandit, Pranav, Thierry Hoch, Pauline Ezanno, François Beaudeau, and Elisabeta Vergu. 2016. "Spread of Coxiella Burnetii between Dairy Cattle Herds in an Enzootic Region: Modelling Contributions of Airborne Transmission and Trade." Veterinary Research 47(1):48.

Quast, Megan, Chithra Sreenivasan, Gabriel Sexton, Hunter Nedland, Aaron Singrey, Linda Fawcett, Grant Miller, Dale Lauer, Shauna Voss, Stacy Pollock, Cristina W. Cunha, Jane ChristopherHennings, Eric Nelson, and Feng Li. 2015. "Serological Evidence for the Presence of Influenza D Virus in Small Ruminants." Veterinary Microbiology 180(3-4):281-85.

Rosignoli C, Faccini S, Merenda M, Chiapponi C, De Mattia A, Bufalo G, Garbarino C, Baioni L, Bolzoni L, Nigrelli A, Foni E. 2017. "Influenza D Virus Infection in Cattle in Italy." Large Animal Review 23:123-28. 
Salem, Elias, Elizabeth A. J. Cook, Hicham Ait Lbacha, Justine Oliva, Félix Awoume, Gilbert L. Aplogan, Emmanuel Couacy Hymann, Dishon Muloi, Sharon L. Deem, Said Alali, Zaid Zouagui, Eric M. Fèvre, Gilles Meyer, and Mariette F. Ducatez. 2017. "Serologic Evidence for Influenza c and d Virus among Ruminants and Camelids, Africa, 1991-2015." Emerging Infectious Diseases 23(9):1556-59.

Salem, Elias, Sara Hägglund, Hervé Cassard, Tifenn Corre, Katarina Näslund, Charlotte Foret, David Gauthier, Anne Pinard, Maxence Delverdier, Siamak Zohari, Jean-François Valarcher, Mariette Ducatez, and Gilles Meyer. 2019. "Pathogenesis, Host Innate Immune Response, and Aerosol Transmission of Influenza D Virus in Cattle." Journal of Virology 93(7).

Sayers, R. G., G. P. Sayers, J. F. Mee, M. Good, M. L. Bermingham, J. Grant, and P. G. Dillon. 2013. "Implementing Biosecurity Measures on Dairy Farms in Ireland." Veterinary Journal 197(2):25967.

Silveira, Simone, Shollie M. Falkenberg, Bryan S. Kaplan, Beate Crossley, Julia F. Ridpath, Fernando B. Bauermann, Charles P. Fossler, David A. Dargatz, Rohana P. Dassanayake, Amy L. Vincent, Cláudio W. Canal, and John D. Neill. 2019. "Serosurvey for Influenza D Virus Exposure in Cattle, United States, 2014-2015." Emerging Infectious Diseases 25(11):2074-80.

Snoeck, Chantal J., Justine Oliva, Maude Pauly, Serge Losch, Félix Wildschutz, Claude P. Muller, Judith M. Hübschen, and Mariette F. Ducatez. 2018. "Influenza D Virus Circulation in Cattle and Swine, Luxembourg, 2012-2016." Emerging Infectious Diseases 24(7):1-3.

Song, Hao, Jianxun Qi, Zahra Khedri, Sandra Diaz, Hai Yu, Xi Chen, Ajit Varki, Yi Shi, and George F. Gao. 2016. “An Open Receptor-Binding Cavity of Hemagglutinin-Esterase-Fusion Glycoprotein from Newly-Identified Influenza D Virus: Basis for Its Broad Cell Tropism." PLoS Pathogens 12(1).

Sreenivasan, Chithra C., Milton Thomas, Radhey S. Kaushik, Dan Wang, and Feng Li. 2019. "Influenza a in Bovine Species: A Narrative Literature Review." Viruses 11(6).

Su, Shuo, Xinliang Fu, Gairu Li, Fiona Kerlin, and Michael Veit. 2017. “Novel Influenza D Virus: Epidemiology, Pathology, Evolution and Biological Characteristics." Virulence 8(8):1580-91.

Trombetta, Claudia M., Serena Marchi, Ilaria Manini, Otfried Kistner, Feng Li, Pietro Piu, Alessandro Manenti, Fabrizio Biuso, Chithra Sreenivasan, Julian Druce, and Emanuele Montomoli. 2019. “Influenza D Virus: Serological Evidence in the Italian Population from 2005 to 2017." Viruses $12(1)$.

White, Sarah K., Wenjun Ma, Clinton J. McDaniel, Gregory C. Gray, and John A. Lednicky. 2016. 
"Serologic Evidence of Exposure to Influenza D Virus among Persons with Occupational Contact with Cattle." Journal of Clinical Virology 81:31-33.

Zhai, Shao Lun, He Zhang, Sheng Nan Chen, Xia Zhou, Tao Lin, Runxia Liu, Dian Hong Lv, Xiao Hui Wen, Wen Kang Wei, Dan Wang, and Feng Li. 2017. "Influenza D Virus in Animal Species in Guangdong Province, Southern China." Emerging Infectious Diseases 23(8):1392-96.

Zhang, Maodong, Janet E. Hill, Champika Fernando, Trevor W. Alexander, Edouard Timsit, Frank van der Meer, and Yanyun Huang. 2019. "Respiratory Viruses Identified in Western Canadian Beef Cattle by Metagenomic Sequencing and Their Association with Bovine Respiratory Disease." Transboundary and Emerging Diseases 66(3):1379-86. 


\begin{tabular}{|c|c|c|c|c|c|c|c|c|c|}
\hline $\begin{array}{l}\text { Year of } \\
\text { sampling }\end{array}$ & Country & Region/Department & $\begin{array}{c}\text { Type of } \\
\text { Surveillan- } \\
\text { ce }\end{array}$ & $\begin{array}{c}\text { Nr. } \\
\text { herds }\end{array}$ & $\begin{array}{l}\mathrm{Nr} . \\
\text { collected } \\
\text { sera }\end{array}$ & $\begin{array}{l}\text { Nr. of } \\
\text { positive } \\
\text { sera }\end{array}$ & $\begin{array}{l}\% \text { of IDV } \\
\text { positive } \\
\text { sera }\end{array}$ & Screening method & Reference \\
\hline 2014-2018 & $\mathrm{FR}$ & Occitanie & active ${ }^{\dagger}$ & 31 & 1409 & 248 & 48.2 & HI assay (1\% HRBCs) & Oliva et al., 2019 \\
\hline 2014-2015 & FR & Nord, Hauts-de-France & active ${ }^{\dagger}$ & 6 & 477 & 112 & 31.0 & HI assay (1\% HRBCs) & Oliva et al., 2019 \\
\hline 2015 & FR & Vendée, Pays de la Loire & Active ${ }^{\dagger}$ & 8 & 480 & 308 & 70.0 & HI assay (1\% HRBCs) & Oliva et al., 2019 \\
\hline 2017-2018 & FR & $\begin{array}{c}\text { Côte d'Or, Bourgogne } \\
\text { Franche-Comté }\end{array}$ & active ${ }^{\dagger}$ & 20 & 480 & 158 & 39.6 & HI assay (1\% HRBCs) & Oliva et al., 2019 \\
\hline 2016 & FR & Bretagne & active ${ }^{\dagger}$ & 27 & 480 & 168 & 45.2 & HI assay (1\% HRBCs) & Oliva et al., 2019 \\
\hline 2013 & IT & Northern Italy, po valley & active ${ }^{\dagger}$ & 35 & 945 & 903 & 95.6 & $\begin{array}{c}\text { HI assay }(0.5 \% \\
\text { TRBCs) }\end{array}$ & Unpublished data \\
\hline 2015 & IT & Mantua, Lombardy & active ${ }^{\dagger}$ & 42 & 420 & 398 & 92.4 & $\begin{array}{l}\text { HI assay }(0.5 \% \\
\text { TRBCs) }\end{array}$ & Rosignoli et al., 2017 \\
\hline 2016-2018 & IT & $\begin{array}{l}\text { Northern Italy (Po } \\
\text { Valley) }\end{array}$ & passive ${ }^{\dagger}$ & 44 & 914 & 634 & 69.0 & $\begin{array}{l}\text { HI assay }(0.5 \% \\
\text { TRBCs) }\end{array}$ & Unpublished data \\
\hline 2016-2017 & IT & $\begin{array}{l}\text { Northern Italy (Po } \\
\text { Valley) }\end{array}$ & both + & 31 & 315 & 233 & 74.0 & Competitive ELISA & Moreno et al., 2019 \\
\hline 2016-2018 & IT & $\begin{array}{l}\text { Northern Italy (Po } \\
\text { Valley) }\end{array}$ & activeף & 29 & 556 & 493 & 88.6 & $\begin{array}{l}\text { HI assay }(0.5 \% \\
\text { TRBCs) }\end{array}$ & Unpublished data \\
\hline 2016 & LU & Whole country & active ${ }^{\dagger}$ & 44 & 450 & 361 & 80.2 & HI assay (1\% HRBCs) & Snoeck et al.. 2018 \\
\hline 2019 & LU & Whole country & active ${ }^{\dagger}$ & 64 & 1108 & 914 & 82.5 & Competitive ELISA & Unpublished data \\
\hline 2017 & IE & Whole country & activet & & 1219 & 1153 & 94.6 & $\begin{array}{c}\text { HI assay }(0.75 \% \\
\text { TRBCs) }\end{array}$ & O’Donovan et al., 2019 \\
\hline 2017 & IE & Whole country & passive ${ }^{\dagger}$ & & 1183 & 768 & 64.9 & $\begin{array}{c}\text { HI assay }(0.75 \% \\
\text { TRBCs) }\end{array}$ & O’Donovan et al.,2019 \\
\hline
\end{tabular}

+ While surveillance for IDV was carried out from animals with/without respiratory clinical signs, none of the sera was collected specifically for IDV seroprevalence studies (rather co-products from infectious bovine rhinitis or swine influenza surveillance programs mainly): surveillance stands for observational study here.

I Sera collected specifically for an IDV seroprevalence study.

Table 1. Overview over available serological results in cattle in France, Italy, Luxembourg and Ireland; abbreviations: FR France, IT Italy, LU Luxembourg, IE Ireland, HI Hemagglutination Inhibition. ELISA Enzyme-linked immunosorbent assay. HRBCs Horse Red Blood Cells. TRBCs Turkey Red Blood cells 


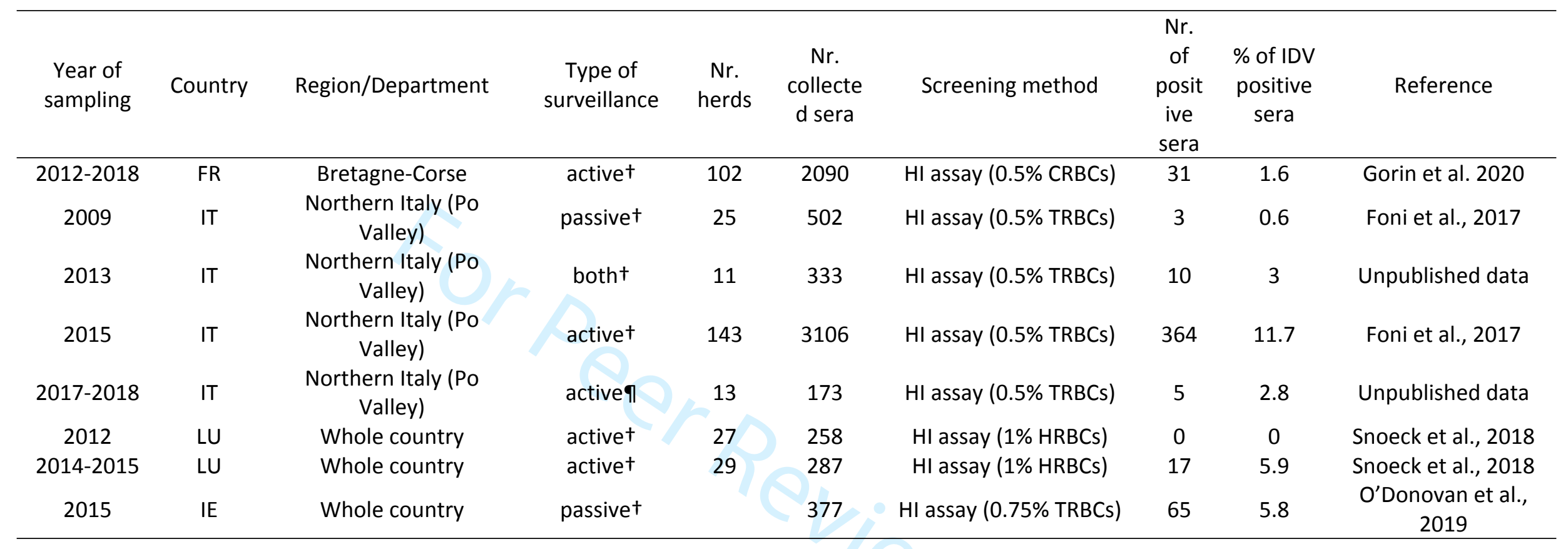

Table 2. Overview over available serological results in swine in France, Italy, Luxembourg and Ireland; abbreviations: FR France, IT Italy, LU Luxembourg, IE Ireland, HI Hemagglutination Inhibition, CRBCs Chicken Red Blood Cells, HRBCs Horse Red Blood Cells, TRBCs Turkey Red Blood Cells 


\begin{tabular}{|c|c|c|c|c|c|c|c|c|c|}
\hline $\begin{array}{l}\text { Year of } \\
\text { sampling }\end{array}$ & Country & Region/Department & $\begin{array}{c}\text { Type of } \\
\text { surveillance }\end{array}$ & $\begin{array}{l}\text { Nr. of } \\
\text { herds }\end{array}$ & $\begin{array}{l}\text { Nr. collected } \\
\text { sera and } \\
\text { species }\end{array}$ & Screening method & $\begin{array}{c}\text { Nr. of } \\
\text { positive } \\
\text { sera }\end{array}$ & $\begin{array}{c}\% \text { of IDV } \\
\text { positive } \\
\text { sera }\end{array}$ & Reference \\
\hline 2016 & $F R$ & Bretagne & active & 4 & 164 (sheep) & $\mathrm{HI}$ assay (1\% HRBCs) & 0 & 0 & Oliva et al., 2019 \\
\hline $\begin{array}{l}2014- \\
2015\end{array}$ & FR & Hauts-de-France & active & 7 & 306 (sheep) & $\mathrm{HI}$ assay (1\% HRBCs) & 16 & 5.5 & Oliva et al., 2019 \\
\hline 2015 & FR & Hauts-de-France & active & 1 & 80 (goat) & $\mathrm{HI}$ assay (1\% HRBCs) & 1 & 1.3 & Oliva et al., 2019 \\
\hline $\begin{array}{l}2014- \\
2018\end{array}$ & FR & Occitanie & active & 10 & 441 (goat) & $\mathrm{HI}$ assay (1\% HRBCs) & 12 & 2.9 & Oliva et al., 2019 \\
\hline $\begin{array}{l}2016- \\
2017\end{array}$ & IT & $\begin{array}{l}\text { Northern Italy (Po } \\
\text { Valley) }\end{array}$ & active & 7 & 506 (sheep) & $\begin{array}{l}\text { HI assay }(0.5 \% \\
\text { TRBCs) }\end{array}$ & 32 & 6.3 & Unpublished data \\
\hline $\begin{array}{l}2016- \\
2017\end{array}$ & IT & $\begin{array}{c}\text { Northern Italy (Po } \\
\text { Valley) }\end{array}$ & active & 4 & 188 (goat) & $\begin{array}{c}\mathrm{HI} \text { assay }(0.5 \% \\
\text { TRBCs) }\end{array}$ & 6 & 3.1 & Unpublished data \\
\hline
\end{tabular}

Table 3. Overview over available serological results in small ruminants (ovine and caprine species) in France, Italy, and Ireland; abbreviations:

FR France, IT Italy, IE Ireland, HI Hemagglutination Inhibition, HRBCs Horse Red Blood Cells, TRBCs Turkey Red Blood Cells 


\section{Figure legends}

Figure 1. Cattle trade in the European Union (2018) A) Trade matrix showing commercial exchanges of cattle for production in 2018 among EU member countries (source: ec.europa.eu). On the $Y$ axis the cattle origin country is represented, on the $X$ axis the destination country is showed. The figure legend on the right hand side of the matrix represents the number of exchanged animals. Country names were expressed with two letters of the official ISO code for European Union countries. B) Histogram showing the number of exported cattle for production in 2018 in different EU member states. C) Histogram showing the number of imported cattle for production in 2018 in different EU member states.

Figure 2. Swine trade in the European Union (2018) A) Trade matrix showing commercial exchanges of swine for production in 2018 among EU member countries (source: ec.europa.eu). On the $Y$ axis the cattle origin country is represented, on the $X$ axis the destination country is showed. The figure legend on the right hand side of the matrix represents the number of exchanged animals. Country names were expressed with two letters of the official ISO code for European Union countries. B) Histogram showing the number of exported swine heads for production in 2018 in different EU member states. C) Histogram showing the number of imported swine heads for production in 2018 in different EU member states.

Figure 3. Map of Europe representing cattle commercial trades for production among different countries in $\mathbf{2 0 1 8}$ (source: ec.europa.eu). The map only shows cattle that has been transported for production. Countries in colour represent areas where IDV seroprevalence has been investigated. Dark red arrows represent cattle movements that include more than 500 '000 heads (France-to-Italy direction was highlighted with a bigger arrow, indicating the biggest trade above all in Europe). Blue arrows indicate cattle movements with more than 30 '000 heads per year (for simplicity, only trades including more than 30 thousand heads are shown). 
A Cattle trade for production in EU members (2018)

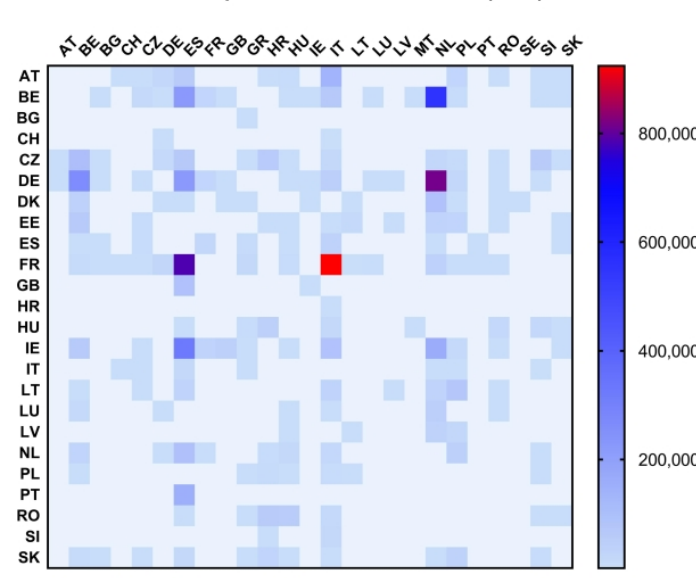

B
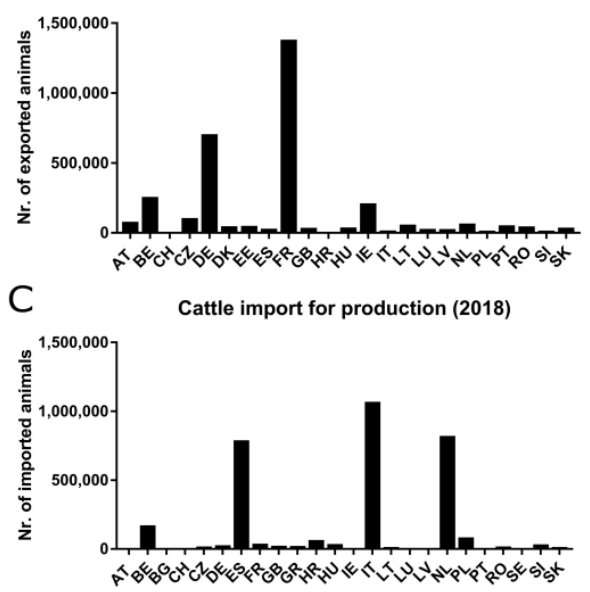

Figure 1. Cattle trade in the European Union (2018) A) Trade matrix showing commercial exchanges of cattle for production in 2018 among EU member countries (source: ec.europa.eu). On the Y axis the cattle origin country is represented, on the $X$ axis the destination country is showed. The figure legend on the right hand side of the matrix represents the number of exchanged animals. Country names were expressed with two letters of the official ISO code for European Union countries. B) Histogram showing the number of exported cattle for production in 2018 in different EU member states. C) Histogram showing the number of imported cattle for production in 2018 in different EU member states.

$$
272 \times 135 \mathrm{~mm}(600 \times 600 \mathrm{DPI})
$$


A Swine export for production (2018)

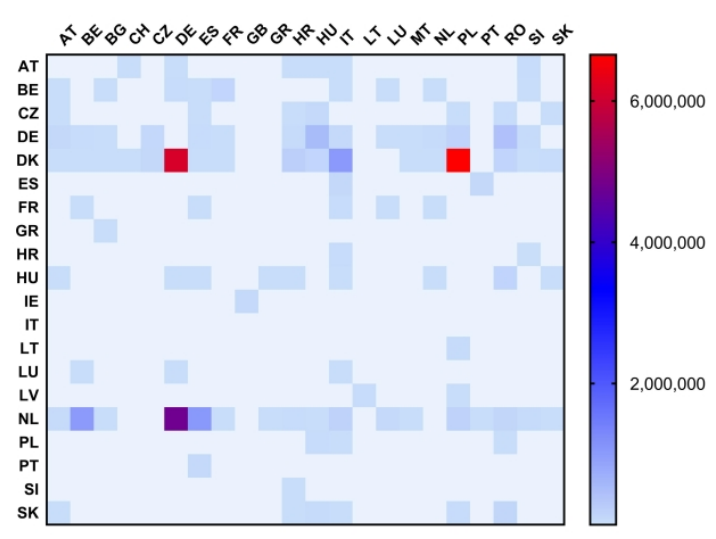

B

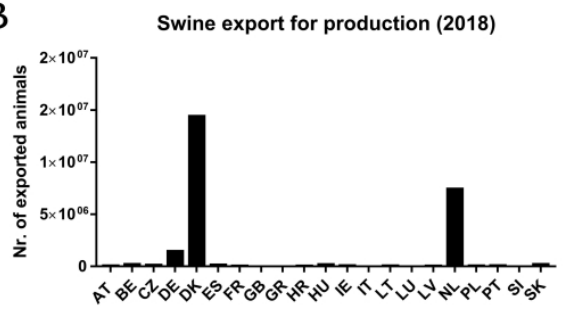

C

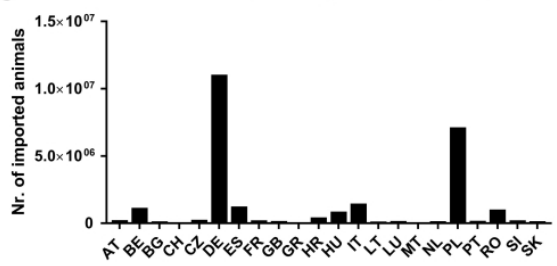

Figure 2. Swine trade in the European Union (2018) A) Trade matrix showing commercial exchanges of swine for production in 2018 among EU member countries (source: ec.europa.eu). On the Y axis the cattle origin country is represented, on the $X$ axis the destination country is showed. The figure legend on the right hand side of the matrix represents the number of exchanged animals. Country names were expressed with two letters of the official ISO code for European Union countries. B) Histogram showing the number of exported swine heads for production in 2018 in different EU member states. C) Histogram showing the number of imported swine heads for production in 2018 in different EU member states.

$277 \times 135 \mathrm{~mm}(600 \times 600 \mathrm{DPI})$ 


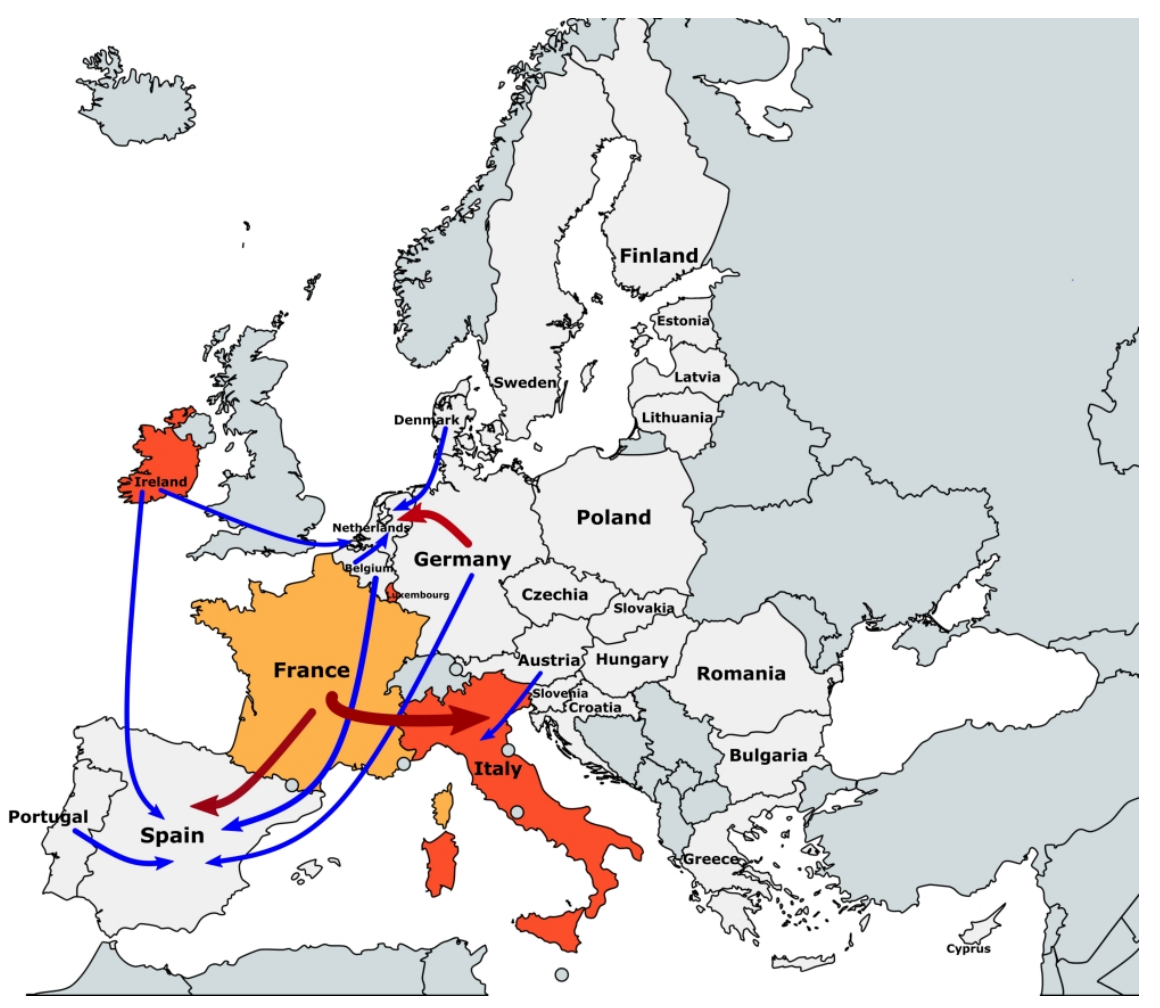

Figure 3. Map of Europe representing cattle commercial trades for production among different countries in 2018 (source: ec.europa.eu). The map only shows cattle that has been transported for production. Countries in colour represent areas where IDV seroprevalence has been investigated. Dark red arrows represent cattle movements that include more than 500'000 heads (France-to-Italy direction was highlighted with a bigger arrow, indicating the biggest trade above all in Europe). Blue arrows indicate cattle movements with more than $30^{\prime} 000$ heads per year (for simplicity, only trades including more than 30 thousand heads are shown). 


\title{
Title: Emerging Influenza D virus infection in European livestock as determined in serology studies: are we underestimating its spread over the continent?
}

\begin{abstract}
Authors: M. Gaudino ${ }^{1,{ }^{*}}$, A. Moreno $2,{ }^{*}$, C.J. Snoeck ${ }^{3,}{ }^{*}$, S. Zohari ${ }^{4}$, C. Saegerman ${ }^{5}$, T. O'Donovan ${ }^{6}$, E. Ryan ${ }^{6}$, I. Zanni ${ }^{7}$, E. Foni ${ }^{7}$, A. Sausy ${ }^{3}$, J. Hübschen ${ }^{3}$, G. Meyer ${ }^{1}$, C. Chiapponi ${ }^{7}{ }^{*}$, M.F. Ducatez ${ }^{1}{ }^{*}$
\end{abstract}

Authors affiliations:

${ }^{1}$ IHAP, Université de Toulouse, INRAE, ENVT, Toulouse, France

2 Istituto Zooprofilattico Sperimentale della Lombardia e dell'Emilia Romagna "Bruno Ubertini", Brescia, Italy

${ }^{3}$ Clinical and Applied Virology group, Department of Infection and Immunity, Luxembourg Institute of Health, Esch-sur-Alzette, Luxembourg

${ }^{4}$ National Veterinary Institute, Uppsala, Sweden

${ }^{5}$ Fundamental and Applied Research for Animals and Health (FARAH) Center, University of Liège, Liège, Belgium

${ }^{6}$ Central Veterinary Research Laboratory, Celbridge, Co. Kildare, Ireland

7 Istituto Zooprofilattico Sperimentale della Lombardia e dell'Emilia Romagna "Bruno Ubertini", Parma, Italy

* These authors equally contributed to the study and should be considered as co-first/co-last authors 


\section{Summary (252 words)}

Influenza D virus (IDV) is a novel orthomyxovirus that was first isolated in 2011 in the United States from a swine exhibiting Influenza-like disease. To date, its detection is extended to all continents and in a broad host range: IDV is circulating in cattle, swine, feral swine, camelids, small ruminants and horses. Evidence also suggests a possible species jump to humans, underlining the issue of zoonotic potential. In Europe, serological investigations in cattle have partially allowed the understanding of the virus diffusion in different countries such as Italy, France, Luxembourg and Ireland. The infection is widespread in cattle but limited in other investigated species, consolidating the assumption of cattle as IDV primary host. We hypothesize that commercial livestock trade could play a role in the observed differences in IDV seroprevalence among these areas. Indeed, the overall level of exposure in cattle and swine in destination countries (e.g. Italy) is higher than in origin countries (e.g. France), leading to the hypothesis of a viral shedding following the transportation of young cattle abroad and thus contributing to larger diffusion at countries of destination. IDV large geographic circulation in cattle from Northern to more Southern European countries also supports the hypothesis of a viral spread through livestock trade. This review summarizes available data on IDV seroprevalence in Europe collected so far and integrates unpublished data from IDV European surveillance framework of the last decade. In addition, the possible role of livestock trade and biosecurity measures in this pathogen's spread is discussed.

Keywords: Influenza D virus, seroprevalence, epidemiology, zoonosis, livestock trade, cattle, swine, small ruminants 


\section{Introduction}

Influenza D virus (IDV) was isolated for the first time in 2011 in the United States from a swine exhibiting Influenza-like syndrome (Hause et al. 2013). It shared $50 \%$ of genetic identity with human Influenza C virus (ICV), leading to its provisional designation as C/swine/Oklahoma/1334/2011. In addition, this novel virus showed no reassortment with the other genera of Influenza viruses (Influenza A and B viruses, IAV and IBV, or ICV) (Hause et al. 2014). As a consequence, the International Committee on Taxonomy of Viruses (ICTV) decided in 2016 to create a new genus in the Influenza virus family. The new genus is currently known as Influenza D virus, extending therefore the Orthomyxoviridae from six to seven genera. Based on their similarity in terms of genetic and morphological structures, some authors suggested the possibility of IDV derivation from ICV (Su et al. 2017). Indeed, the nucleotide identity between ICV and IDV is $50 \%$ for the Hemagglutinin Esterase-Fusion segment (HEF), the most variable segment among Influenza viruses, and 70\% for PB1 (Polymerase basic protein 1), the most conserved segment (Hause et al., 2013). Similarities between ICV and IDV include the genomic composition of seven segments and both only have one major surface glycoprotein that fulfils the functions of receptor recognition and binding, its destruction and the fusion between the virions and the host cell membranes. On the contrary, IAV and IBV are composed of eight genomic segments and these functions are accomplished by two different proteins, the hemagglutinin (HA), which binds to the host cell receptors and mediates the membrane fusion, and neuraminidase (NA) that allows for receptor destroying and new viral particles release (Asha and Kumar 2019).

So far, two major circulating IDV lineages have been described in North America and Europe, often designated as $D / O K$ and $D / 660$. Reassortment events between these two lineages were also revealed (Chiapponi et al. 2019; Collin et al. 2015). In Europe, a third genetically divergent lineage was described in France in 2012 and Ireland in 2014 (designated as D/bovine/France/2986/2012 and D/bovine/Ireland/007780/2014 respectively). Though, further IDV sequences are needed to assess if another different lineage is circulating in Europe. In addition, other genetically divergent lineages are present in Japan and they have not been reported on other continents to date (Murakami et al. 2016, 2020)(Hayakawa et al. 2020). 
So far, IDV seems to have a broad host range and has been described almost on all continents, showing an intercontinental transmission. Despite its first isolation from swine, cattle is currently considered as IDV principal host. Indeed, various studies report a high prevalence of IDV in this species (Luo et al., 2017; O’Donovan, Donohoe, Ducatez, Meyer, \& Ryan, 2019; Oliva et al., 2019; Rosignoli et al., 2017) whereas historically cattle had never been considered a potential reservoir of Influenza A viruses (Sreenivasan et al. 2019). Currently, the list of susceptible species include cattle, swine (Foni et al. 2017; Gorin et al. 2019), small ruminants (O’Donovan et al. 2019; Oliva et al. 2019; Quast et al. 2015), camelids (Murakami et al. 2019; Salem et al. 2017), feral swine (Ferguson et al. 2018) and horses (Nedland et al. 2018). The emergence of the novel IDV in pigs initially raised public health concerns, as swine is a wellknown host of other zoonotic Influenza viruses. However, whether IDV could be a threat to human is still unclear. Studies in the ferret model, where IDV replicates efficiently (Hause et al. 2013), as well as IDV receptors characterization (Song et al. 2016), suggest that humans may be susceptible. Furthermore, IDV replicates well in a human airway epithelium model (Holwerda et al. 2019) and its genetic material has been detected in a bioaerosol sample collected at an airport (Bailey et al. 2018), in a hospital emergency room (Choi et al. 2018), as well as in a nasal swab of a farmer working on a pig farm in Malaysia (Borkenhagen et al. 2018). Serologic surveys conducted in persons with occupational contact with cattle in Florida (White et al. 2016) and in the general population in Italy (Trombetta et al. 2019) suggested a zoonotic potential. In contrast, a prevalence of only $1.3 \%$ of anti-IDV antibodies was initially observed in a Canadian elderly cohort (Hause et al. 2013) and cross-reactivity between anti-ICV and IDV antibodies was highlighted in human and camelids, suggesting that further controls and optimizations should be carried out in the serology assays before conclusions can be drawn on IDV seropositivity in these species (Eckard 2016; Salem et al. 2017). Wide epidemiological investigations are still lacking to assess a risk level for humans and they could provide additional insights about the real IDV zoonotic potential.

Epidemiological investigations suggest cattle to be IDV primary host and, so far, the virus has been detected both in healthy and diseased animals. Nevertheless, studies conducted through metagenomic approaches suggested its implication in Bovine Respiratory Disease Complex (BRDC) (Mitra et al. 2016; Ng et al. 2015; Zhang et al. 2019), one of the most concerning health issues in cattle industry that has multifactorial aetiology and causes major economic losses. 
Experimental infections showed mild to moderate clinical signs in cattle, as well as direct contact and aerosol transmission among animals (Ferguson et al. 2016; Salem et al. 2019). The real implication of IDV on BRDC severity in the field is still not clear and further studies would be needed to demonstrate its role.

In Europe, IDV was first reported in cattle in France in 2012 (Ducatez, Pelletier, and Meyer 2015) and was then detected in surrounding countries Italy (Chiapponi et al. 2016) and Luxembourg (Snoeck et al. 2018), but also in Ireland (Flynn et al. 2018) and the UK (Dane et al. 2019). On this continent, as in other parts of the world, the livestock trade across national borders each year is of great importance. Livestock trade essentially includes import and export of live animals to neighbouring countries for production (fattening), breeding and slaughtering. This sector substantially contributes to the European economy, representing almost half of the total agricultural activity (Eurostat). In a "One Health" context, livestock health is a major link in the global health chain. Animal-based product consumption has been a fast-growing component of food industry in the last decades, particularly in some developing countries in Asia and South America but concerning also industrialized countries. A continuous surveillance on emerging livestock pathogens is thus required in order to ensure animal wellbeing but also to prevent health-related challenges in a more complex setting of animal-tohuman pathogen transmission prevention.

The aim of this review is to summarize IDV infection spread in the European continent in different animal species. The review focuses on serological data obtained during the last ten years of surveillance and includes unpublished data coming from the consortium for European surveillance of this novel virus. In addition, the role of livestock trade in IDV transmission between different countries is discussed.

\section{IDV seroprevalence in European livestock: a widespread infection in cattle with limited diffusion in swine and small ruminants}

IDV seroprevalence in different species (which will be detailed in the following paragraphs) was mainly assessed by $\mathrm{HI}$ assay (Hemagglutination Inhibition). In all cases, a threshold of positivity was set at antibody titers $\geq 1: 20$. ELISA test (Enzyme-linked Immunosorbent Assay) 
was also used. A summary of technical details and results for each study is presented in Table 1 (Cattle), Table 2 (Swine) and Table 3 (Small ruminants).

\section{Cattle}

In France, a serosurvey was carried out on bovine sera ( $n=3703$ ) collected from 2014 to 2018 in 5 French regions (Oliva et al. 2019). Sera were tested by $\mathrm{HI}$ assay (with 1\% solution of horse red blood cells). All animals were older than 1-year of age, excluding interference with maternally derived antibodies. The overall resulting seroprevalence was $47.2 \%$ but results varied depending on the geographical region (with seroprevalence ranging from 31.0 to 70.0\%). In Italy, the overall reported IDV seroprevalence in cattle was higher than in France. Cohorts of bovine sera coming from both active $(n=420)$ (Rosignoli et al., 2017) and both active/passive surveillance ( $n=315)$ (Moreno et al. 2019) were tested for anti-IDV antibodies by using $\mathrm{HI}$ assay ( $0.5 \%$ solution of turkey red blood cells) and solid-phase competitive ELISA (Moreno et al, 2019). Overall resulting seroprevalence was $92.4 \%$ and $74 \%$, respectively. In addition, an observational cohort study conducted on 914 cattle samples collected in 20162018 showed a seroprevalence of 69\%. In Luxembourg high IDV seroprevalence (80.2-82.5\%) was found in cattle sera ( $n=450$ and $n=108$ ) collected in 2016 (Snoeck et al. 2018) and 2019 respectively. Authors reported no difference between IDV seroprevalence in dairy and meat production cattle. Similar seroprevalence rates were found when testing the same 2016 cohort by $\mathrm{HI}(80.2 \%)$ or solid-phase competitive ELISA (81.8\%). Finally, in 2017 in Ireland (O'Donovan et al. 2019) sera were collected from slaughterhouses across the country $(n=1219)$ and screened for anti-IDV antibodies. An additional cohort of sera collected in 2016 and 2017 for diagnostic purposes to screen for antibodies to bovine respiratory disease (BRD) pathogens was also tested for IDV antibodies ( $n=1183)$. A high difference was found in terms of seroprevalence between the two cohorts, with $94.6 \%$ and $64.9 \%$ for active and passive surveillance, respectively. Relevant differences in overall IDV seroprevalence in cattle were also found in Italy based on the type of surveillance (active or passive), suggesting that it could be a relevant factor that should be taken into consideration to assess future sampling plans. Available serological results in cattle in Europe are summarized in Table 1.

\section{Swine}


A different scenario emerged from serological studies conducted on serum samples collected in swine farms. A serosurvey across France was conducted on 2090 sera collected from 102 different farms between 2012 and 2018 (Gorin et al. 2019). Herds were mostly located in Brittany region, known to have the highest pig density in France. Samples were also collected in Nouvelle Aquitaine, Occitanie, Hauts-de-France, Normandie, Pays de la Loire and Corsica regions. While anti-IDV antibodies in cattle were found in most of these regions (Oliva et al. 2019), positive swine sera were found only from Brittany and Corsica regions. The overall IDV seroprevalence was $1.6 \%$ (represented by 31 positive samples on a total of 2090 tested sera). In these two regions, seroprevalence varied from 3.3 to $73.3 \%$ in Brittany and $7.1-16.7 \%$ in Corsica. In Brittany two herds with high within-herd seroprevalence (73.3\% and 3.3\%, where samples were collected in 2014 and 2015 respectively) were re-tested in 2017 to assess virus persistence but they then exhibited 13.3\% and 3.3\%. In Italy, cohorts from 2009 to 2018 coming from active and passive surveillance were screened for anti-IDV antibodies. All herds originated from the Po Valley (Northern Italy), one of the most intensive pig farming areas in Europe. Overall IDV seroprevalence ranged from 0.6 to $11.7 \%$, depending on the year of sampling (Foni et al. 2017). IDV monitoring was also conducted on wild boars from the Alpine and Northern Apennine areas. A total of 1350 samples collected in 2018 and 2019 was tested with a low prevalence (1,92\%). Details of sera tested for Italian cohorts for each year are available in Table 2. In Luxembourg, the first cohort from 2012 ( $n=258)$ was found seronegative, then a second cohort $(n=287)$ including sera collected at slaughter in 2014-2015 harboured 5.9\% seroprevalence (Snoeck et al. 2018). In Ireland, a seroprevalence of 5.8\% was found in swine ( $n=377$ ) (O'Donovan et al. 2019). Results from serological studies in pigs are summarized in Table 2.

\section{Small ruminants}

So far, limited serological investigations have been performed on small ruminants. In France, sheep and goat sera were tested within the same framework as IDV serosurveillance in cattle (Oliva et al. 2019). In Brittany, no evidence of past exposure was found in sheep sera cohorts $(n=164)$, whereas in goats $(n=104) 5.8 \%$ of samples tested positive. In Hauts-de-France, 5.5\% $(n=306)$ and $1.3 \%(n=80)$ of sheep and goats were seropositive, respectively. In Occitanie, the overall seroprevalence was $0.4 \%(n=960)$ for sheep and $2.9 \%(n=441)$ for goats. The authors 
reported a significant difference between IDV seroprevalence in cattle and small ruminants in these regions. Similar results in seroprevalence were found in Italy in sheep $(n=506)$ and goats ( $n=188$ ) cohorts of sera collected in $2016-2017$, with $6.3 \%$ and $3.1 \%$ of tested sera IDV seropositive, respectively (unpublished data). A very low prevalence of $0.98 \%$ was observed when wild ungulates $(n=204)$ collected under the Italian wildlife monitoring program were tested (unpublished data). Finally, in Ireland a seroprevalence of $4.5 \%(n=288)$ was reported in sheep (O'Donovan et al. 2019). Results from serological studies in small ruminants are summarized in Table 3.

Taken together, high IDV seroprevalence in cattle suggested the potential role of the species as primary host of this emerging virus, while available data on pigs and small ruminants suggest that its circulation is limited in these species. Overall the median IDV seroprevalence was significantly higher in cattle than in swine and small ruminants (Kruskal-Wallis equalityof-populations rank test; chi-squared $=24$ with 2 d.f. and $p$-value $=0.0001$ ) but they are not significant between swine and small ruminants (Kruskal-Wallis equality-of-populations rank test; chi-squared $=0.009$ with 1 d.f. and $p$-value $=0.92$ ). High IDV seroprevalence in European cattle is consistent with the findings generated in other continents: in the United States the overall IDV seroprevalence in cattle was $77.5 \%$ nationally, ranging from $47.7 \%$ to $84.6 \%$ depending on the region (Silveira et al. 2019), whereas in South America $73 \%$ of tested farms had at least one positive animal (Alvarez et al. 2020). The infection seems less extended in cattle in African countries (Salem et al. 2017; Fusade-Boyer et al. 2020) than in Europe or America. This could be possibly due to a lower density of animals in cattle industry, as cattle density was found to be a major risk factor for IDV infection occurrence (Fusade-Boyer et al. 2020). Although some studies highlighted IDV circulation in Asian countries by using molecular tools (Murakami et al. 2016; Zhai et al. 2017), little data on IDV seroprevalence in cattle is available for this continent at the moment. In Japan, a recent study highlighted IDV seroprevalence ranging from $45 \%$ to $71 \%$ in sera collected in Hokkaido prefecture from 2009 to 2018 (Hayakawa et al. 2020), underlining the virus circulation on the island for at least ten years.

\section{Overview on livestock trade between different countries in Europe}


The European Union has a substantial livestock population: in 2018, Europe counted 148 million heads of pigs, 87 of cattle, 98 of sheep and goats (Eurostat 2018). The most important cattle producer is France, reaching 19 million heads of animals in 2018 (Eurostat), followed by Germany (12 million heads). A considerable number of animals is then exported to neighbouring countries, mostly for production but also for slaughtering and for breeding. In 2018, 3,073,082 cattle heads were traded among EU countries for production, 654,938 heads for slaughtering and 607,226 for breeding. The most important movements of cattle for production took place from France to Italy (almost one million heads), followed by Germany to the Netherlands $(531,597$ heads), France to Spain $(420,774$ heads) and Belgium to the Netherlands (153,508 heads). This makes Italy, Netherlands and Spain the three most important cattle importers in Europe and France and Germany the leading countries for export. A different situation is observed in export for slaughtering: the Netherlands is the leading country for export, Austria and Belgium for import. Cattle trade between different EU countries is summarized in a trade matrix in Figure 1 and on a geographic map in Figure 3.

With regards to swine production, Spain and Germany are leading countries for pig farming, reaching a population of 30,804,102 and 26,445,400 heads in 2018, respectively. In Europe, the total number of traded pigs has greater importance than cattle: in $2018,8,388,712$ heads were traded for slaughter, 24,279,371 were traded for production and 752,501 for breeding. Among pigs traded for production, the vast majority is exported abroad by Denmark, with more than 14 million heads per year, followed by Netherlands ( 7 million per year). European countries importing most swine are Germany (almost 11 million heads per year) and Poland (7 million heads per year) (Eurostat). Swine trade between different EU countries is summarized in a trade matrix in Figure 2.

Among small ruminants, sheep occupy a much more important place on the market of traded animals than goats. Sheep are mostly traded in Europe for slaughtering, with a total of 2,442,066 heads in 2018 (mostly from France to Spain, UK to Ireland and Hungary to Italy). Also 932,946 heads were traded for fattening (mostly from Spain to Portugal and from Romania to Greece and Hungary). Trade for sheep breeding concerned only 48,104 heads overall. Finally, 25,330 goats were traded for slaughtering, 8,409 for fattening and 4,840 for breeding (Eurostat). 


\section{Discussion}

Livestock trade is of great economic importance, allowing animal-origin products offer at affordable price for the final consumer, as well as a substantial contribution to the local economy and development. Nevertheless, live animal transport can also lead to health issues that are often only noticed at the destination country. Transport is a very stressful event for animals, with a clear impact on cattle health and production and has a well-documented role in BRDC onset (Buckham Sporer et al. 2008; Van Engen and Coetzee 2018). Transportation can cause immunosuppression in young calves, allowing for the colonization by opportunistic pathogens and sometimes causing severe disease (Earley, Buckham Sporer, and Gupta 2017). Pathogen shedding following transportation has been demonstrated to increase, not only for bacteria such as Mannhemia haemolytica, Mycoplasma bovis and Pasteurella multocida but also for viruses such as Bovine Coronavirus (BCoV) and Bovine Respiratory Syncytial Virus (BRSV) (Cirone et al. 2019). Most importantly, in a study conducted in Mississippi, young calves were sampled before and after admission in herd facility for anti-IDV antibodies and viral RNA detection (Ferguson et al. 2015). Results showed that IDV infection could occur after arrival in the conditioning yard, as some calves tested negative before the arrival by RT-PCR but were positive one week later. In addition, the same study showed that almost all neonatal calves were able to acquire anti-IDV antibodies through colostrum after birth but the antibody titers seemed to decrease with age, as at 6 to 8 months only 3.7 to $11.5 \%$ of the same calves were IDV seropositive. Seropositivity increased then at 1-year age, suggesting that calves mostly encounter IDV between 6 months to one year of age. In Europe, this often corresponds to the period where calves are transported abroad for fattening but also slaughtering, strengthening the hypothesis that trading of young calves in a period of immunologic weakness could contribute to pathogen shedding in the herd of arrival.

In this context, biosecurity is an important measure to prevent livestock pest and disease introduction in farms. In European regulations, biosecurity is defined in the "Animal Health Law" and other legislation aimed at minimising animal disease contained in Regulation (EU) 2016/429. On a practical level, some of the recommended practices include isolation for at least 4 weeks for all purchased animals arriving at a farm but also regular equipment sanitation, correct storage of food and water and, when applicable, preventive measures such as vaccination. There are different individuals that play a role in biosecurity implementation, 
including not only government authorities and legislators but above all farmers and veterinarians. It is often assumed that farmers have the necessary resources and knowledge to minimize the risk of disease introduction. In a survey conducted on dairy cattle farmers in Ireland, most of the interviewees declared that biosecurity is important. Still, half of them also declared a lack of necessary knowledge that would help them in improving their biosecurity measures (Sayers et al. 2013). In addition, a lack of trust of farmers towards governing authorities was shown, arising the belief that biosecurity is primarily a government responsibility, and leading to inobservance of recommended good practices (Higgins et al. 2018).

As IDV is an emerging pathogen, its veterinary monitoring is still partial. Its novelty and the possible absence of clinical manifestation in infected cattle impair early pathogen detection without specific molecular tools and active surveillance. Although IDV does not cause concerns for cattle farming to date despite its implication in BRDC, there is a need for a more rigorous surveillance and implementation of biosecurity measures. In particular, observance of recommended practices such as quarantine for purchased animals and testing on the arriving lots is once more advised (Damiaans et al. 2020), as a survey showed that only half of the interviewed farmers apply the quarantine practice and only $7 \%$ test animals after purchase (Sayers et al. 2013). Among interviewed farmers answering "no" to the post-purchase testing, $21 \%$ of them thought it was of "no benefit", $20 \%$ declared "not to know what to test for", $45 \%$ were never advised to do so and $13 \%$ complained about the cost of testing.

Interestingly, the overall IDV prevalence was found to be lower in countries that mainly export cattle (e.g. France, with a seroprevalence ranging from $33 \%$ to $64 \%$ depending on the region) than in countries that mainly import cattle from abroad, from instance Italy (from $65 \%$ to 95\%). This suggests that cattle may come in contact with IDV during or just after transportation and that viral shedding mainly occurs after transportation in the destination countries, contributing to larger diffusion than in origin countries. The role of inter-herd livestock exchanges in disease spread is already known, being of particular concern for airborne transmission pathogens (Pandit et al. 2016). The assumption of IDV spread though livestock trade is also strengthened by the large diffusion in cattle across all Europe, from Northern to more Southern. The high movement of cattle from France to Italy could have contributed to IDV spread in this country. IDV introduction in Ireland and Luxembourg could have occurred 
through the import of infected cattle from France or other European countries. Considering the large number of traded animals every year, we speculate that IDV is probably present also outside the four territories surveyed, as already suggested previously for countries bordering Luxembourg given frequent cross-border grazing and trade (Snoeck et al., 2018). A surveillance network extended to other EU members would provide more information about the real spread of this emerging pathogen, in particular in countries importing cattle from areas where IDV is already known to circulate. For instance, IDV surveillance could be useful in leading countries for cattle import in Europe, such as Spain and the Netherlands, where a similar (or even higher) seroprevalence than the origin country could be hypothesized. In addition, a longitudinal study with monitoring of IDV in calves traded from origin country to arrival country would provide additional insight about the real shedding of this pathogen during transport. IDV surveillance implementation is justified by its zoonotic potential and its possible implication in BRDC aggravation.

\section{Conclusion}

Influenza D virus infection in cattle has spread across different countries in Europe. Surveillance in countries where IDV presence has not been investigated is required in order to understand the real spread of the virus. IDV role in BRDC onset, especially after stress transport experience, is still not clear to date and further analysis could help in determining its actual implication in diseased cattle. We hypothesize the role of livestock trade in the observed differences of IDV seroprevalence among European countries where data is available. In addition to surveillance, implementation of biosecurity measures are once more emphasized (Damiaans et al. 2020), especially at arrival of young cattle in a facility, in order to limit the geographical spread of this emerging respiratory pathogen with zoonotic potential.

\section{Acknowledgements}

This study was performed under the Grant Agreement Number GP/EFSA/AFSCO/2017/01 GA04, entitled "Risk assessment for influenza D in Europe". This work was co-funded by the French National Agency for Research, project ANR-15-CE35-0005 "FLUD", the Italian Ministry of Health grant IZS LER 2015006 RC and Istituto Zooprofilattico Sperimentale della Lombardia e dell'Emilia Romagna, the Luxembourg Institute of Health, the Ministère de l'Agriculture, 
Viticulture et Développement Rural du Luxembourg, the Department of Agriculture, Food and the Marine, Ireland. The article reflects only the author's view and the EFSA Authority is not responsible for any use that may be made of the information it contains.

\section{Ethics statement}

The authors confirm that the ethical policies of the journal, as noted on the journal's author guidelines page, have been adhered to. No ethical approval was required as this is a review article.

\section{Conflict of interest statement}

The authors declare that they have no competing interests

\section{Data sharing and accessibility}

For the most part, data sharing is not applicable to this article as little new data were created or analyzed in this study. The unpublished data that support the findings of this study are available from the corresponding author upon reasonable request.

\section{References}

Alvarez, Ignacio J., Marcelo Fort, Juan Pasucci, Fabiana Moreno, Hugo Gimenez, Katarina Näslund, Sara Hägglund, Siamak Zohari, and Jean François Valarcher. 2020. "Seroprevalence of Influenza D Virus in Bulls in Argentina." Journal of Veterinary Diagnostic Investigation 32(4):585-88.

Asha, Kumari, and Binod Kumar. 2019. “Emerging Influenza D Virus Threat: What We Know so Far!" Journal of Clinical Medicine 8(2):192.

Bailey, Emily S., Jessica Y. Choi, Juliana Zemke, Myagmarsukh Yondon, and Gregory C. Gray. 2018. "Molecular Surveillance of Respiratory Viruses with Bioaerosol Sampling in an Airport." Tropical Diseases, Travel Medicine and Vaccines 4(1). 
Borkenhagen, Laura K., Kerry A. Mallinson, Rick W. Tsao, Siaw Jing Ha, Wei Honn Lim, Teck Hock Toh, Benjamin D. Anderson, Jane K. Fieldhouse, Sarah E. Philo, Kuek Sen Chong, William G. Lindsley, Alejandro Ramirez, James F. Lowe, Kristen K. Coleman, and Gregory C. Gray. 2018. "Surveillance for Respiratory and Diarrheal Pathogens at the Human-Pig Interface in Sarawak, Malaysia." PLoS ONE 13(7).

Buckham Sporer, K. R., P. S. D. Weber, J. L. Burton, B. Earley, and M. A. Crowe. 2008. "Transportation of Young Beef Bulls Alters Circulating Physiological Parameters That May Be Effective Biomarkers of Stress." Journal of Animal Science 86(6):1325-34.

Chiapponi, Chiara, Silvia Faccini, Alice Fusaro, Ana Moreno, Alice Prosperi, Marianna Merenda, Laura Baioni, Valentina Gabbi, Carlo Rosignoli, Giovanni L. Alborali, Lara Cavicchio, Isabella Monne, Camilla Torreggiani, Andrea Luppi, and Emanuela Foni. 2019. "Detection of a New Genetic Cluster of Influenza D Virus in Italian Cattle." Viruses 11(12).

Chiapponi, Chiara, Silvia Faccini, Aurora De Mattia, Laura Baioni, Ilaria Barbieri, Carlo Rosignoli, Arrigo Nigrelli, and Emanuela Foni. 2016. "Detection of Influenza D Virus among Swine and Cattle, Italy." Emerging Infectious Diseases 22(2):352-54.

Choi, Jessica Y., Juliana Zemke, Sarah E. Philo, Emily S. Bailey, Myagmarsukh Yondon, and Gregory C. Gray. 2018. "Aerosol Sampling in a Hospital Emergency Room Setting: A Complementary Surveillance Method for the Detection of Respiratory Viruses." Frontiers in Public Health 6.

Cirone, Francesco, Barbara Padalino, Daniele Tullio, Paolo Capozza, Michele Lo Surdo, Gianvito Lanave, and Annamaria Pratelli. 2019. "Prevalence of Pathogens Related to Bovine Respiratory Disease before and after Transportation in Beef Steers: Preliminary Results." Animals 9(12).

Collin, Emily A., Zizhang Sheng, Yuekun Lang, Wenjun Ma, Ben M. Hause, and Feng Li. 2015. "Cocirculation of Two Distinct Genetic and Antigenic Lineages of Proposed Influenza D Virus in Cattle." Journal of Virology 89(2):1036-42.

Damiaans, Bert, Véronique Renault, Steven Sarrazin, Anna Catharina Berge, Bart Pardon, Claude Saegerman, and Jeroen Dewulf. 2020. "A Risk-Based Scoring System to Quantify Biosecurity in Cattle Production." Preventive Veterinary Medicine 179.

Dane, Hannah, Catherine Duffy, Maria Guelbenzu, Ben Hause, Sean Fee, Fiona Forster, Michael J. McMenamy, and Ken Lemon. 2019. "Detection of Influenza D Virus in Bovine Respiratory Disease Samples, UK." Transboundary and Emerging Diseases 66(5):2184-87.

Ducatez, Mariette F., Claire Pelletier, and Gilles Meyer. 2015. "Influenza d Virus in Cattle, France, 
2011-2014." Emerging Infectious Diseases 21(2):368-71.

Earley, B., K. Buckham Sporer, and S. Gupta. 2017. “Invited Review: Relationship between Cattle Transport, Immunity and Respiratory Disease." Pp. 486-92 in Animal. Vol. 11. Cambridge University Press.

Eckard, Laura Evelyn. 2016. "Assessment of the Zoonotic Potential of a Novel Bovine Influenza Virus."

Van Engen, N. K., and J. F. Coetzee. 2018. "Effects of Transportation on Cattle Health and Production: A Review." Animal Health Research Reviews 19(2):142-54.

Ferguson, Lucas, Laura Eckard, William B. Epperson, Li Ping Long, David Smith, Carla Huston, Suzanne Genova, Richard Webby, and Xiu Feng Wan. 2015. “Influenza D Virus Infection in Mississippi Beef Cattle." Virology 486:28-34.

Ferguson, Lucas, Kaijian Luo, Alicia K. Olivier, Fred L. Cunningham, Sherry Blackmon, Katie HansonDorr, Hailiang Sun, John Baroch, Mark W. Lutman, Bianca Quade, William Epperson, Richard Webby, Thomas J. DeLiberto, and Xiu Feng Wan. 2018. “Influenza D Virus Infection in Feral Swine Populations, United States." Emerging Infectious Diseases 24(6):1020-28.

Ferguson, Lucas, Alicia K. Olivier, Suzanne Genova, William B. Epperson, David R. Smith, Liesel Schneider, Kathleen Barton, Katlin McCuan, Richard J. Webby, and Xiu-Feng Wan. 2016. “Pathogenesis of Influenza D Virus in Cattle." Journal of Virology 90(12):5636-42.

Flynn, Orla, Clare Gallagher, Jean Mooney, Claire Irvine, Mariette Ducatez, Ben Hause, Guy McGrath, and Eoin Ryan. 2018. "Influenza D Virus in Cattle, Ireland." Emerging Infectious Diseases 24(2):389-91.

Foni, Emanuela, Chiara Chiapponi, Laura Baioni, Irene Zanni, Marianna Merenda, Carlo Rosignoli, Constantinos S. Kyriakis, Mario Vittorio Luini, Maria Lucia Mandola, Luca Bolzoni, Arrigo Daniele Nigrelli, and Silvia Faccini. 2017. "Influenza D in Italy: Towards a Better Understanding of an Emerging Viral Infection in Swine." Scientific Reports 7(1).

Fusade-Boyer, Maxime, Pidemnéwé S. Pato, Mathias Komlan, Koffi Dogno, Komla Batawui, Emilie GoMaro, Pamela McKenzie, Claire Guinat, Aurélie Secula, Mathilde Paul, Richard J. Webby, Annelise Tran, Agnès Waret-Szkuta, and Mariette F. Ducatez. 2020. "Risk Mapping of Influenza D Virus Occurrence in Ruminants and Swine in Togo Using a Spatial Multicriteria Decision Analysis Approach." Viruses 12(2):16-18.

Gorin, Stéphane, Christelle Fablet, Stéphane Quéguiner, Nicolas Barbier, Frédéric Paboeuf, Séverine Hervé, Nicolas Rose, and Gaëlle Simon. 2019. “Assessment of Influenza D Virus in Domestic Pigs 
and Wild Boars in France: Apparent Limited Spread within Swine Populations despite Serological Evidence of Breeding Sow Exposure." Viruses 12(1).

Hause, Ben M., Emily A. Collin, Runxia Liu, Bing Huang, Zizhang Sheng, Wuxun Lu, Dan Wang, Eric A. Nelson, and Feng Li. 2014. “Characterization of a Novel Influenza Virus in Cattle and Swine: Proposal for a New Genus in the Orthomyxoviridae Family." MBio 5(2).

Hause, Ben M., Mariette Ducatez, Emily A. Collin, Zhiguang Ran, Runxia Liu, Zizhang Sheng, Anibal Armien, Bryan Kaplan, Suvobrata Chakravarty, Adam D. Hoppe, Richard J. Webby, Randy R. Simonson, and Feng Li. 2013. "Isolation of a Novel Swine Influenza Virus from Oklahoma in 2011 Which Is Distantly Related to Human Influenza C Viruses." PLoS Pathogens 9(2).

Hayakawa, Jun, Tomomi Masuko, Tae Takehana, and Tohru Suzuki. 2020. "Genetic and Antigenic Characterization and Retrospective Surveillance of Bovine Influenza D Viruses Identified in Hokkaido, Japan from 2018 to 2020." Viruses 12(8):877.

Higgins, Vaughan, Melanie Bryant, Marta Hernandez-Jover, Luzia Rast, and Connar McShane. 2018. "Devolved Responsibility and On-Farm Biosecurity : Practices of Biosecure Farming Care in Livestock Production." Sociologia Ruralis 58(1).

Holwerda, Melle, Jenna Kelly, Laura Laloli, Isabel Stürmer, Jasmine Portmann, Hanspeter Stalder, and Ronald Dijkman. 2019. "Determining the Replication Kinetics and Cellular Tropism of Influenza D Virus on Primary Well-Differentiated Human Airway Epithelial Cells." Viruses 11(4).

Luo, Junrong, Lucas Ferguson, David R. Smith, Amelia R. Woolums, William B. Epperson, and Xiu Feng Wan. 2017. "Serological Evidence for High Prevalence of Influenza D Viruses in Cattle, Nebraska, United States, 2003-2004." Virology 501:88-91.

Mitra, Namita, Natalia Cernicchiaro, Siddartha Torres, Feng Li, and Ben M. Hause. 2016.

"Metagenomic Characterization of the Virome Associated with Bovine Respiratory Disease in Feedlot Cattle Identified Novel Viruses and Suggests an Etiologic Role for Influenza D Virus." Journal of General Virology 97(8):1771-84.

Moreno, Ana, Davide Lelli, Antonio Lavazza, Enrica Sozzi, Irene Zanni, Chiara Chiapponi, Emanuela Foni, Lorenzo Capucci, and Emiliana Brocchi. 2019. "MAb-Based Competitive ELISA for the Detection of Antibodies against Influenza D Virus." Transboundary and Emerging Diseases 66(1):268-76.

Murakami, Shin, Maiko Endoh, Tomoya Kobayashi, Akiko Takenaka-Uema, James K. Chambers, Kazuyuki Uchida, Masugi Nishihara, Benjamin Hause, and Taisuke Horimoto. 2016. "Influenza d 
Virus Infection in Herd of Cattle, Japan." Emerging Infectious Diseases 22(8):1517-19.

Murakami, Shin, Tomoha Odagiri, Simenew Keskes Melaku, Boldbaatar Bazartseren, Hiroho Ishida, Akiko Takenaka-Uema, Yasushi Muraki, Hiroshi Sentsui, and Taisuke Horimoto. 2019. "Influenza D Virus Infection in Dromedary Camels, Ethiopia." Emerging Infectious Diseases 25(6):1224-25.

Murakami, Shin, Ryota Sato, Hiroho Ishida, Misa Katayama, Akiko Takenaka-Uema, and Taisuke Horimoto. 2020. "Influenza d Virus of New Phylogenetic Lineage, Japan." Emerging Infectious Diseases 26(1):168-71.

Nedland, H., J. Wollman, C. Sreenivasan, M. Quast, A. Singrey, L. Fawcett, J. Christopher-Hennings, E. Nelson, R. S. Kaushik, D. Wang, and F. Li. 2018. "Serological Evidence for the Co-Circulation of Two Lineages of Influenza D Viruses in Equine Populations of the Midwest United States." Zoonoses and Public Health 65(1):e148-54.

$\mathrm{Ng}$, Terry Fei Fan, Nikola O. Kondov, Xutao Deng, Alison Van Eenennaam, Holly L. Neibergs, and Eric Delwart. 2015. "A Metagenomics and Case-Control Study To Identify Viruses Associated with Bovine Respiratory Disease." Journal of Virology 89(10):5340-49.

O’Donovan, Tom, Leah Donohoe, Mariette F. Ducatez, Gilles Meyer, and Eoin Ryan. 2019.

"Seroprevalence of Influenza D Virus in Selected Sample Groups of Irish Cattle, Sheep and Pigs." Irish Veterinary Journal 72(1).

Oliva, Justine, Amit Eichenbaum, Jade Belin, Maria Gaudino, Jean Guillotin, Jean Pierre Alzieu, Philippe Nicollet, Roland Brugidou, Eric Gueneau, Evelyne Michel, Gilles Meyer, and Mariette F. Ducatez. 2019. "Serological Evidence of Influenza D Virus Circulation among Cattle and Small Ruminants in France." Viruses 11(6).

Pandit, Pranav, Thierry Hoch, Pauline Ezanno, François Beaudeau, and Elisabeta Vergu. 2016. "Spread of Coxiella Burnetii between Dairy Cattle Herds in an Enzootic Region: Modelling Contributions of Airborne Transmission and Trade." Veterinary Research 47(1):48.

Quast, Megan, Chithra Sreenivasan, Gabriel Sexton, Hunter Nedland, Aaron Singrey, Linda Fawcett, Grant Miller, Dale Lauer, Shauna Voss, Stacy Pollock, Cristina W. Cunha, Jane ChristopherHennings, Eric Nelson, and Feng Li. 2015. "Serological Evidence for the Presence of Influenza D Virus in Small Ruminants." Veterinary Microbiology 180(3-4):281-85.

Rosignoli C, Faccini S, Merenda M, Chiapponi C, De Mattia A, Bufalo G, Garbarino C, Baioni L, Bolzoni L, Nigrelli A, Foni E. 2017. "Influenza D Virus Infection in Cattle in Italy." Large Animal Review 23:123-28. 
Salem, Elias, Elizabeth A. J. Cook, Hicham Ait Lbacha, Justine Oliva, Félix Awoume, Gilbert L. Aplogan, Emmanuel Couacy Hymann, Dishon Muloi, Sharon L. Deem, Said Alali, Zaid Zouagui, Eric M. Fèvre, Gilles Meyer, and Mariette F. Ducatez. 2017. "Serologic Evidence for Influenza c and d Virus among Ruminants and Camelids, Africa, 1991-2015." Emerging Infectious Diseases 23(9):1556-59.

Salem, Elias, Sara Hägglund, Hervé Cassard, Tifenn Corre, Katarina Näslund, Charlotte Foret, David Gauthier, Anne Pinard, Maxence Delverdier, Siamak Zohari, Jean-François Valarcher, Mariette Ducatez, and Gilles Meyer. 2019. "Pathogenesis, Host Innate Immune Response, and Aerosol Transmission of Influenza D Virus in Cattle." Journal of Virology 93(7).

Sayers, R. G., G. P. Sayers, J. F. Mee, M. Good, M. L. Bermingham, J. Grant, and P. G. Dillon. 2013. "Implementing Biosecurity Measures on Dairy Farms in Ireland." Veterinary Journal 197(2):25967.

Silveira, Simone, Shollie M. Falkenberg, Bryan S. Kaplan, Beate Crossley, Julia F. Ridpath, Fernando B. Bauermann, Charles P. Fossler, David A. Dargatz, Rohana P. Dassanayake, Amy L. Vincent, Cláudio W. Canal, and John D. Neill. 2019. "Serosurvey for Influenza D Virus Exposure in Cattle, United States, 2014-2015." Emerging Infectious Diseases 25(11):2074-80.

Snoeck, Chantal J., Justine Oliva, Maude Pauly, Serge Losch, Félix Wildschutz, Claude P. Muller, Judith M. Hübschen, and Mariette F. Ducatez. 2018. "Influenza D Virus Circulation in Cattle and Swine, Luxembourg, 2012-2016." Emerging Infectious Diseases 24(7):1-3.

Song, Hao, Jianxun Qi, Zahra Khedri, Sandra Diaz, Hai Yu, Xi Chen, Ajit Varki, Yi Shi, and George F. Gao. 2016. “An Open Receptor-Binding Cavity of Hemagglutinin-Esterase-Fusion Glycoprotein from Newly-Identified Influenza D Virus: Basis for Its Broad Cell Tropism." PLoS Pathogens 12(1).

Sreenivasan, Chithra C., Milton Thomas, Radhey S. Kaushik, Dan Wang, and Feng Li. 2019. "Influenza a in Bovine Species: A Narrative Literature Review." Viruses 11(6).

Su, Shuo, Xinliang Fu, Gairu Li, Fiona Kerlin, and Michael Veit. 2017. “Novel Influenza D Virus: Epidemiology, Pathology, Evolution and Biological Characteristics." Virulence 8(8):1580-91.

Trombetta, Claudia M., Serena Marchi, Ilaria Manini, Otfried Kistner, Feng Li, Pietro Piu, Alessandro Manenti, Fabrizio Biuso, Chithra Sreenivasan, Julian Druce, and Emanuele Montomoli. 2019. “Influenza D Virus: Serological Evidence in the Italian Population from 2005 to 2017.” Viruses 12(1).

White, Sarah K., Wenjun Ma, Clinton J. McDaniel, Gregory C. Gray, and John A. Lednicky. 2016. 
"Serologic Evidence of Exposure to Influenza D Virus among Persons with Occupational Contact with Cattle." Journal of Clinical Virology 81:31-33.

Zhai, Shao Lun, He Zhang, Sheng Nan Chen, Xia Zhou, Tao Lin, Runxia Liu, Dian Hong Lv, Xiao Hui Wen, Wen Kang Wei, Dan Wang, and Feng Li. 2017. "Influenza D Virus in Animal Species in Guangdong Province, Southern China." Emerging Infectious Diseases 23(8):1392-96.

Zhang, Maodong, Janet E. Hill, Champika Fernando, Trevor W. Alexander, Edouard Timsit, Frank van der Meer, and Yanyun Huang. 2019. "Respiratory Viruses Identified in Western Canadian Beef Cattle by Metagenomic Sequencing and Their Association with Bovine Respiratory Disease." Transboundary and Emerging Diseases 66(3):1379-86. 


\begin{tabular}{|c|c|c|c|c|c|c|c|c|c|}
\hline $\begin{array}{l}\text { Year of } \\
\text { sampling }\end{array}$ & Country & Region/Department & $\begin{array}{c}\text { Type of } \\
\text { Surveillan- } \\
\text { ce }\end{array}$ & $\begin{array}{l}\text { Nr. } \\
\text { herds }\end{array}$ & $\begin{array}{l}\mathrm{Nr} . \\
\text { collected } \\
\text { sera }\end{array}$ & $\begin{array}{c}\text { Nr. of } \\
\text { positive } \\
\text { sera }\end{array}$ & $\begin{array}{l}\% \text { of IDV } \\
\text { positive } \\
\text { sera }\end{array}$ & Screening method & Reference \\
\hline $2014-2018$ & FR & Occitanie & activet & 31 & 1409 & 248 & 48.2 & HI assay (1\% HRBCs) & Oliva et al., 2019 \\
\hline 2014-2015 & FR & Nord, Hauts-de-France & active ${ }^{\dagger}$ & 6 & 477 & 112 & 31.0 & HI assay (1\% HRBCs) & Oliva et al., 2019 \\
\hline 2015 & FR & Vendée, Pays de la Loire & Active ${ }^{\dagger}$ & 8 & 480 & 308 & 70.0 & HI assay (1\% HRBCs) & Oliva et al., 2019 \\
\hline $2017-2018$ & FR & $\begin{array}{l}\text { Côte d'Or, Bourgogne } \\
\text { Franche-Comté }\end{array}$ & active ${ }^{\dagger}$ & 20 & 480 & 158 & 39.6 & HI assay (1\% HRBCs) & Oliva et al., 2019 \\
\hline 2016 & $\mathrm{FR}$ & Bretagne & activet & 27 & 480 & 168 & 45.2 & HI assay (1\% HRBCs) & Oliva et al., 2019 \\
\hline 2013 & IT & Northern Italy, po valley & active ${ }^{\dagger}$ & 35 & 945 & 903 & 95.6 & $\begin{array}{c}\text { HI assay }(0.5 \% \\
\text { TRBCs) }\end{array}$ & Unpublished data \\
\hline 2015 & IT & Mantua, Lombardy & active ${ }^{\dagger}$ & 42 & 420 & 398 & 92.4 & $\begin{array}{c}\text { HI assay }(0.5 \% \\
\text { TRBCs) }\end{array}$ & Rosignoli et al., 2017 \\
\hline $2016-2018$ & IT & $\begin{array}{l}\text { Northern Italy (Po } \\
\text { Valley) }\end{array}$ & passive ${ }^{\dagger}$ & 44 & 914 & 634 & 69.0 & $\begin{array}{c}\text { HI assay }(0.5 \% \\
\text { TRBCs })\end{array}$ & Unpublished data \\
\hline 2016-2017 & IT & $\begin{array}{l}\text { Northern Italy (Po } \\
\text { Valley) }\end{array}$ & both + & 31 & 315 & 233 & 74.0 & Competitive ELISA & Moreno et al., 2019 \\
\hline $2016-2018$ & IT & $\begin{array}{l}\text { Northern Italy (Po } \\
\text { Valley) }\end{array}$ & activeף & 29 & 556 & 493 & 88.6 & $\begin{array}{c}\text { HI assay }(0.5 \% \\
\text { TRBCs) }\end{array}$ & Unpublished data \\
\hline 2016 & LU & Whole country & active ${ }^{+}$ & 44 & 450 & 361 & 80.2 & HI assay (1\% HRBCs) & Snoeck et al.. 2018 \\
\hline 2019 & LU & Whole country & active ${ }^{\dagger}$ & 64 & 1108 & 914 & 82.5 & Competitive ELISA & Unpublished data \\
\hline 2017 & $\mathrm{IE}$ & Whole country & active ${ }^{\dagger}$ & & 1219 & 1153 & 94.6 & $\begin{array}{c}\text { HI assay }(0.75 \% \\
\text { TRBCs })\end{array}$ & O’Donovan et al., 2019 \\
\hline 2017 & $\mathrm{IE}$ & Whole country & passive ${ }^{\dagger}$ & & 1183 & 768 & 64.9 & $\begin{array}{c}\text { HI assay }(0.75 \% \\
\text { TRBCs) }\end{array}$ & O’Donovan et al.,2019 \\
\hline
\end{tabular}

+ While surveillance for IDV was carried out from animals with/without respiratory clinical signs, none of the sera was collected specifically for IDV seroprevalence studies (rather co-products from infectious bovine rhinitis or swine influenza surveillance programs mainly): surveillance stands for observational study here.

In Sera collected specifically for an IDV seroprevalence study.

Table 1. Overview over available serological results in cattle in France, Italy, Luxembourg and Ireland; abbreviations: FR France, IT Italy, LU Luxembourg, IE Ireland, HI Hemagglutination Inhibition. ELISA Enzyme-linked immunosorbent assay. HRBCs Horse Red Blood Cells. TRBCs Turkey Red Blood cells 


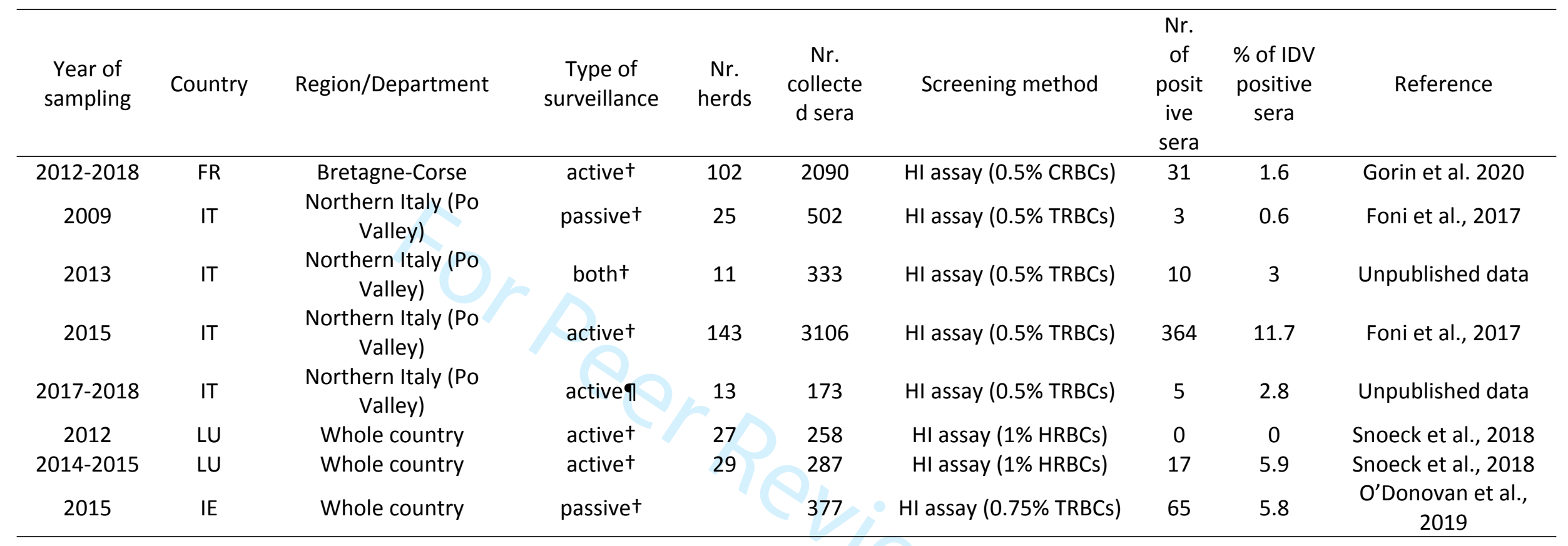

Table 2. Overview over available serological results in swine in France, Italy, Luxembourg and Ireland; abbreviations: FR France, IT Italy, LU Luxembourg, IE Ireland, HI Hemagglutination Inhibition, CRBCs Chicken Red Blood Cells, HRBCs Horse Red Blood Cells, TRBCs Turkey Red Blood Cells 


\begin{tabular}{|c|c|c|c|c|c|c|c|c|c|}
\hline $\begin{array}{l}\text { Year of } \\
\text { sampling }\end{array}$ & Country & Region/Department & $\begin{array}{c}\text { Type of } \\
\text { surveillance }\end{array}$ & $\begin{array}{l}\text { Nr. of } \\
\text { herds }\end{array}$ & $\begin{array}{l}\text { Nr. collected } \\
\text { sera and } \\
\text { species }\end{array}$ & Screening method & $\begin{array}{c}\text { Nr. of } \\
\text { positive } \\
\text { sera }\end{array}$ & $\begin{array}{c}\% \text { of IDV } \\
\text { positive } \\
\text { sera }\end{array}$ & Reference \\
\hline 2016 & $F R$ & Bretagne & active & 4 & 164 (sheep) & $\mathrm{HI}$ assay (1\% HRBCs) & 0 & 0 & Oliva et al., 2019 \\
\hline $\begin{array}{l}2014- \\
2015\end{array}$ & FR & Hauts-de-France & active & 7 & 306 (sheep) & $\mathrm{HI}$ assay (1\% HRBCs) & 16 & 5.5 & Oliva et al., 2019 \\
\hline 2015 & FR & Hauts-de-France & active & 1 & 80 (goat) & $\mathrm{HI}$ assay (1\% HRBCs) & 1 & 1.3 & Oliva et al., 2019 \\
\hline $\begin{array}{l}2014- \\
2018\end{array}$ & FR & Occitanie & active & 10 & 441 (goat) & $\mathrm{HI}$ assay (1\% HRBCs) & 12 & 2.9 & Oliva et al., 2019 \\
\hline $\begin{array}{l}2016- \\
2017\end{array}$ & IT & $\begin{array}{l}\text { Northern Italy (Po } \\
\text { Valley) }\end{array}$ & active & 7 & 506 (sheep) & $\begin{array}{l}\text { HI assay }(0.5 \% \\
\text { TRBCs) }\end{array}$ & 32 & 6.3 & Unpublished data \\
\hline $\begin{array}{l}2016- \\
2017\end{array}$ & IT & $\begin{array}{c}\text { Northern Italy (Po } \\
\text { Valley) }\end{array}$ & active & 4 & 188 (goat) & $\begin{array}{c}\mathrm{HI} \text { assay }(0.5 \% \\
\text { TRBCs) }\end{array}$ & 6 & 3.1 & Unpublished data \\
\hline
\end{tabular}

Table 3. Overview over available serological results in small ruminants (ovine and caprine species) in France, Italy, and Ireland; abbreviations:

FR France, IT Italy, IE Ireland, HI Hemagglutination Inhibition, HRBCs Horse Red Blood Cells, TRBCs Turkey Red Blood Cells 


\section{Figure legends}

Figure 1. Cattle trade in the European Union (2018) A) Trade matrix showing commercial exchanges of cattle for production in 2018 among EU member countries (source: ec.europa.eu). On the $Y$ axis the cattle origin country is represented, on the $X$ axis the destination country is showed. The figure legend on the right hand side of the matrix represents the number of exchanged animals. Country names were expressed with two letters of the official ISO code for European Union countries. B) Histogram showing the number of exported cattle for production in 2018 in different EU member states. C) Histogram showing the number of imported cattle for production in 2018 in different EU member states.

Figure 2. Swine trade in the European Union (2018) A) Trade matrix showing commercial exchanges of swine for production in 2018 among EU member countries (source: ec.europa.eu). On the $Y$ axis the cattle origin country is represented, on the $X$ axis the destination country is showed. The figure legend on the right hand side of the matrix represents the number of exchanged animals. Country names were expressed with two letters of the official ISO code for European Union countries. B) Histogram showing the number of exported swine heads for production in 2018 in different EU member states. C) Histogram showing the number of imported swine heads for production in 2018 in different EU member states.

Figure 3. Map of Europe representing cattle commercial trades for production among different countries in $\mathbf{2 0 1 8}$ (source: ec.europa.eu). The map only shows cattle that has been transported for production. Countries in colour represent areas where IDV seroprevalence has been investigated. Dark red arrows represent cattle movements that include more than 500 '000 heads (France-to-Italy direction was highlighted with a bigger arrow, indicating the biggest trade above all in Europe). Blue arrows indicate cattle movements with more than 30 '000 heads per year (for simplicity, only trades including more than 30 thousand heads are shown). 